\title{
Periplasmic nitrate reductase revisited: a sulfur atom completes the sixth coordination of the catalytic molybdenum
}

\author{
Shabir Najmudin · Pablo J. González · José Trincão $\cdot$ Catarina Coelho • \\ Abhik Mukhopadhyay • Nuno M. F. S. A. Cerqueira - Carlos C. Romão · \\ Isabel Moura · José J. G. Moura · Carlos D. Brondino · Maria J. Romão
}

Received: 13 December 2007 / Accepted: 21 February 2008/Published online: 8 March 2008

(C) SBIC 2008

\begin{abstract}
Nitrate reductase from Desulfovibrio desulfuricans ATCC 27774 (DdNapA) is a monomeric protein of $80 \mathrm{kDa}$ harboring a bis(molybdopterin guanine dinucleotide) active site and a $[4 \mathrm{Fe}-4 \mathrm{~S}]$ cluster. Previous electron paramagnetic resonance (EPR) studies in both catalytic and inhibiting conditions showed that the molybdenum center has high coordination flexibility when reacted with reducing agents, substrates or inhibitors. As-prepared DdNapA samples, as well as those reacted with substrates and inhibitors, were crystallized and the corresponding structures were solved at resolutions ranging from 1.99 to $2.45 \AA$. The good quality of the diffraction data allowed us to perform a detailed structural study of the active site and, on that basis, the sixth molybdenum ligand, originally
\end{abstract}

S. Najmudin · P. J. González · J. Trincão · C. Coelho ·

A. Mukhopadhyay - N. M. F. S. A. Cerqueira - I. Moura ·

J. J. G. Moura · M. J. Romão ( $₫)$

Departamento de Química, FCT-UNL,

REQUIMTE/CQFB,

Monte de Caparica,

2829-516 Almada, Portugal

e-mail: mromao@dq.fct.unl.pt

S. Najmudin

e-mail: shabir@dq.fct.unl.pt

C. C. Romão

Instituto de Tecnologia Química e Biológica da

Universidade Nova de Lisboa,

Av da República, EAN,

2780-157 Oeiras, Portugal

C. D. Brondino ( $\square)$

Departamento de Física,

Facultad de Bioquímica y Ciencias Biológicas,

Universidad Nacional del Litoral,

3000ZAA Santa Fe, Argentina

e-mail: brondino@fbcb.unl.edu.ar proposed to be an $\mathrm{OH} / \mathrm{OH}_{2}$ ligand, was assigned as a sulfur atom after refinement and analysis of the $B$ factors of all the structures. This unexpected result was confirmed by a single-wavelength anomalous diffraction experiment below the iron edge $(\lambda=1.77 \AA)$ of the as-purified enzyme. Furthermore, for six of the seven datasets, the S-S distance between the sulfur ligand and the $S \gamma$ atom of the molybdenum ligand $\mathrm{Cys}_{\mathrm{A} 140}$ was substantially shorter than the van der Waals contact distance and varies between 2.2 and $2.85 \AA$, indicating a partial disulfide bond. Preliminary EPR studies under catalytic conditions showed an EPR signal designated as a turnover signal ( $g$ values 1.999 , $1.990,1.982$ ) showing hyperfine structure originating from a nucleus of unknown nature. Spectropotentiometric studies show that reduced methyl viologen, the electron donor used in the catalytic reaction, does not interact directly with the redox cofactors. The turnover signal can be obtained only in the presence of the reaction substrates. With use of the optimized conditions determined by spectropotentiometric titration, the turnover signal was developed with ${ }^{15} \mathrm{~N}$-labeled nitrate and in $\mathrm{D}_{2} \mathrm{O}$-exchanged DdNapA samples. These studies indicate that this signal is not associated with a $\mathrm{Mo}(\mathrm{V})$-nitrate adduct and that the hyperfine structure originates from two equivalent solvent-exchangeable protons. The new coordination sphere of molybdenum proposed on the basis of our studies led us to revise the currently accepted reaction mechanism for periplasmic nitrate reductases. Proposals for a new mechanism are discussed taking into account a molybdenum and ligandbased redox chemistry, rather than the currently accepted redox chemistry based solely on the molybdenum atom.

Keywords Periplasmic nitrate reductase - Molybdenum . Electron paramagnetic resonance $\cdot$ X-ray crystallography . Disulfide bond 


\begin{tabular}{|c|c|}
\hline \multicolumn{2}{|c|}{ Abbreviations } \\
\hline Bis-MGD & Bis(molybdopterin guanosine dinucleotide) \\
\hline \multirow[t]{2}{*}{ DdNapA } & Periplasmic nitrate reductase from \\
\hline & Desulfovibrio desulfuricans ATCC 27774 \\
\hline DMSO & Dimethyl sulfoxide \\
\hline DTT & Dithiothreitol \\
\hline EcFdh-H & Formate dehydrogenase from Escherichia coli \\
\hline \multirow[t]{2}{*}{ EcNapA } & Periplasmic nitrate reductase from \\
\hline & Escherichia coli \\
\hline EPR & Electron paramagnetic resonance \\
\hline EXAFS & Extended X-ray absorption fine structure \\
\hline Fdh & Formate dehydrogenase \\
\hline MES & 2-Morpholinoethanesulfonic acid \\
\hline MV & Methyl viologen \\
\hline Nap & Periplasmic nitrate reductase \\
\hline Nar & Respiratory nitrate reductase \\
\hline NR & Nitrate reductase \\
\hline PEG 8K & Poly(ethylene glycol) 8,000 \\
\hline RsNapAB & $\begin{array}{l}\text { Heterodimeric periplasmic nitrate reductase } \\
\text { from Rhodobacter sphaeroides }\end{array}$ \\
\hline SeNarB & Assimilatory nitrate reductase from \\
\hline & Synechococcus elongatus \\
\hline TCEP & Tris(2-carboxyethyl)phosphine hydrochloride \\
\hline Tricine & $N$-Tris(hydroxymethyl)methylglycine \\
\hline
\end{tabular}

\section{Introduction}

Nitrate reductases (NRs) are key enzymes present in the biological cycle of nitrogen [1]. These enzymes catalyze the conversion of nitrate to nitrite according to the reaction

$\mathrm{NO}_{3}{ }^{-}+2 \mathrm{H}^{+}+2 e^{-} \rightarrow \mathrm{NO}_{2}{ }^{-}+\mathrm{H}_{2} \mathrm{O} \quad E^{\circ}=+420 \mathrm{mV}$.

In prokaryotic organisms, this reaction is catalyzed for different purposes by distinct proteins belonging to the dimethyl sulfoxide (DMSO) reductase family of mononuclear molybdenum enzymes that are localized at different compartments of the cell (cytoplasm, membrane or periplasm). The cytoplasmic NRs (assimilatory NRs) are involved in nitrogen assimilation, whereas the membranebound NRs (respiratory NRs, Nar) are required for respiration. Periplasmic NRs (Nap) do not have a well-established function. Different roles such as minimization of the reducing power under certain conditions of growth, denitrification, and scavenging of nitrate have been proposed [2,3].

The crystal structure of Nap from Desulfovibrio desulfuricans ATCC 27774 (DdNapA) was the first reported for a NR [4]. This enzyme is a monomeric protein of $80 \mathrm{kDa}$ harboring a bis(molybdopterin guanine dinucleotide) (bisMGD) active site and a [4Fe-4S] cluster. The molybdenum atom is located at the bottom of an approximately $15 \AA$ deep crevice and is $12 \AA$ away from the $[4 \mathrm{Fe}-4 \mathrm{~S}]$ cluster, which is located near the surface of the protein molecule. The molybdenum ion is coordinated by two dithiolene ligands from the two MGD molecules, a $\mathbf{S} \gamma$ atom from a Cys, and a sixth ligand, which was originally proposed to be a hydroxyl/water molecule [4]. This type of coordination was also proposed in the heterodimeric Nap from Rhodobacter sphaeroides (Rs NapAB) [5], and the Nap from Escherichia coli(EcNapA) [6].

The sixth ligand of molybdenum in the original structure was assigned as a hydroxyl/water molecule (Mo-O distance approximately $2.1 \AA$ ) [4]. However, the crystallographic data reported in the present work provide strong evidence that a heavier element, such as a nonprotein sulfur ligand, is present at the sixth coordination position. We have previously described a similar coordination sphere for the related formate dehydrogenase (Fdh) from $D$. gigas and E. coli $(\mathrm{EcFdh}-\mathrm{H})[7,8]$, in which the main difference is that the Cys sulfur is replaced by a selenium atom from a selenocysteine residue.

In parallel with the X-ray crystallographic studies, electronic paramagnetic resonance (EPR) has been extensively used in the characterization of the molybdenum active site of DdNapA. EPR studies show different types of signals under different experimental conditions [9]. Reduction with dithionite of as-prepared enzyme yields a rhombic EPR signal called "low-potential signal" ( $g$ values $2.016,1.987,1.964)$, which is replaced by the nitrate signal ( $g$ values $2.000,1.990,1.981)$ upon nitrate addition. The nitrate signal also shows a nearly isotropic hyperfine structure of non-solvent-exchangeable nuclear species with $I=1 / 2\left(A_{\mathrm{av}}=4.7 \mathrm{G}\right)$, which is supposed to originate from the hydrogen atoms of the $\beta$-methylene carbon of the coordinated Cys. In contrast, the addition of cyanide to dithionite-reduced NapA, or vice versa, yields a nearly axial EPR Mo(V) signal ( $g$ values 2.024, 2.001, 1.995). Similar situations have been reported for the heterodimeric Nap from Paracoccus pantotrophus [10] and R. sphaeroides [5]. This variability of the electronic properties of the molybdenum active site must be necessarily reflected in its structural properties, which suggests that the active site of these enzymes presents a high flexibility of coordination. Although tentative structures of the EPR-active species in Nap have been proposed [9, 10], a clear correlation between structure and EPR properties has not been clearly established yet and requires further investigation.

The reaction mechanism proposed originally for the reduction of nitrate to nitrite was based on the information extracted from the X-ray structure of DdNapA crystallized in aerobic conditions [4], which was assumed to have the active site in the $\mathrm{Mo}(\mathrm{VI})$ form. In that proposal, the hexacoordinated $\mathrm{Mo}(\mathrm{VI})$ ion is reduced to $\mathrm{Mo}(\mathrm{IV})$ by an external electron donor in a two-electron-transfer reaction mediated by the $[4 \mathrm{Fe}-4 \mathrm{~S}]$ center. The nitrate molecule 
would bind to Mo(IV) ion in the vacant position left by the hydroxyl/water ligand and then two electrons would be transferred from the Mo(IV) to the nitrate molecule with the concomitant release of nitrite and regeneration of the Mo(VI) form of the enzyme. This mechanism, although in line with the accepted general mechanism of molybdenum enzymes [11], is in contrast with electrochemical studies in RsNapAB, EcNapA, and NarB from Synechococcus elongatus ( $\mathrm{SeNarB})[6,12,13]$. These studies indicate that the binding of the nitrate molecule to the molybdenum atom occurs not only in the Mo(IV) form, but also in the $\mathrm{Mo}(\mathrm{V})$ form, thus supporting a reaction scheme which can also occur through two sequential steps of one electron in parallel to the single two-electron step as discussed above. More recently, EPR studies on DdNapA in catalytic conditions detected a novel EPR signal called "turnover" ( $g$ values $1.999,1.990,1.982$ ) which had not been detected for any Nap before [9]. Although these studies were not conclusive regarding the nature of the turnover species, they suggested that the ready state of the enzyme to initiate the reaction might also be the $\operatorname{Mo}(\mathrm{V})$ redox state, which is in line with the electrochemical studies performed on RsNapAB, EcNapA, and SeNarB [6, 12, 13].

In this work, we address several of the issues raised above by using X-ray data combined with EPR measurements of DdNapA, under different experimental conditions. The combination of EPR and X-ray studies has allowed us to understand more about the inhibition mechanism of these enzymes. EPR studies, under turnover conditions, have helped to ascertain the nature of the turnover species. Several X-ray data now available and obtained from as-prepared, EPR-active and inhibited forms of the enzyme, and the high quality of the diffraction data, prompted a detailed analysis that has helped to clarify the true nature of the sixth molybdenum ligand as a sulfur atom, forming a partial disulfide bond with the $S \gamma$ atom of the coordinating Cys. The implications of these results on the reaction mechanism are discussed.

\section{Materials and methods}

\section{Cell cultures and protein purification}

The D. desulfuricans ATCC 27774 cells were grown as described previously, and Nap was purified as reported by González et al. [9] and Liu and Peck [14].

\section{Determination of protein concentration}

The total protein concentration was determined using both the extinction coefficient $\left(\varepsilon_{400 \mathrm{~nm}}=24 \mathrm{mM}^{-1} \mathrm{~cm}^{-1}\right)$ and the bicinchoninic acid kit from Sigma ${ }^{\mathrm{TM}}$.
Samples for EPR spectroscopy

Inhibitor solutions of azide, cyanide, and perchlorate (final concentration $20 \mathrm{mM}$ ) were added to DdNapA samples $(200 \mu \mathrm{M})$ and incubated for $10 \mathrm{~min}$. These samples were reduced with dithionite for $10 \mathrm{~min}$ under anaerobic conditions and frozen for spectral acquisition. Samples were then thawed and air-reoxidized for $10 \mathrm{~min}$ and frozen again for spectrum acquisition. A similar procedure was followed to produce the samples showing the nitrate EPR signal but nitrate (final concentration $100 \mathrm{mM}$ ) was added after dithionite reduction and incubation was under anaerobic conditions for $40 \mathrm{~min}$.

\section{EPR spectroscopy}

X-band spectra were recorded using a Bruker EMX spectrometer equipped with a dual-mode cavity (model ER4116DM) and an Oxford Instruments continuous-flow cryostat. All samples were prepared in $100 \mathrm{mM} \mathrm{N}$ tris(hydroxymethyl)methylglycine (Tricine) $\mathrm{pH} 8.0$ with a protein concentration of $200 \mu \mathrm{M}$. All spectra were obtained in nonsaturating conditions at $100 \mathrm{~K}$. The experimental conditions were microwave frequency $9.65 \mathrm{GHz}$, microwave power $2 \mathrm{~mW}$, modulation amplitude $5 \mathrm{G}$, and modulation field frequency $100 \mathrm{KHz}$. Spin quantification of the $\mathrm{Mo}(\mathrm{V})$ signals was estimated by double integration and comparison with a $1 \mathrm{mM} \mathrm{Cu}$-EDTA standard. Simulations were performed using the program WIN-EPR Simfonia V1.2 from Bruker Instruments. Simulation parameters are given in the caption to Fig. 5.

\section{Spectropotentiometric titration}

Redox titrations were carried out in an anaerobic chamber at room temperature $(298 \mathrm{~K})$ working at a dioxygen concentration below $1 \mathrm{ppm}$. A platinum-silver/silver chloride combined electrode (Crison) was used to determine the electrochemical potential. The samples were incubated in the absence of mediator dyes. The electrochemical potential was dropped using a zinc-reduced methyl viologen (MV) solution $(25 \mathrm{mM})$ dissolved in $100 \mathrm{mM}$ Tricine $\mathrm{pH}$ 8.0. Since the solution of reduced MV is more reactive towards dioxygen than sodium dithionite solutions, all buffers, including the enzyme solution, were dioxygen-degassed with argon and introduced into the anaerobic chamber overnight to ensure that all solutions were dioxygen-free. DdNapA samples $(200 \mu \mathrm{L})$ were taken for EPR spectroscopy in the potential range from $+100 \mathrm{mV}$, the redox potential of the as-prepared solution, to $-400 \mathrm{mV}$ (vs. the normal hydrogen elecrode), the lowest potential reached in these experimental conditions. Samples for EPR spectroscopy were taken after equilibration at each potential and 
frozen in liquid dinitrogen. EPR spectra were recorded as described earlier.

\section{Crystallization, data collection, and processing}

All crystallizations of DdNapA were set up 1-2 days before data collection. Native (as-purified) and cocrystallized (with nitrate, cyanide, azide, or perchlorate) crystals were obtained by hanging drop vapor diffusion, using poly(ethylene glycol) 8,000 (PEG $8 \mathrm{~K} ; 4-15 \% \mathrm{w} / \mathrm{v}$ ) as precipitant, buffered with $0.1 \mathrm{M}$ 2-morpholinoethanesulfonic acid (MES) at pH 6.0-6.5. They were stabilized by adding the crystallization buffer containing either 2-3\% (w/v) extra PEG $8 \mathrm{~K}$ for the native crystals or $10 \mathrm{mM}$ concentrations of the various agents (nitrate, cyanide, azide or perchlorate) to the drop over a period of $10 \mathrm{~min}$ to $2 \mathrm{~h}$. The cocrystallized nitrate crystals were also soaked with $10 \mathrm{mM}$ nitrate, nitrite, arsenite, cyanide, or azide in the cryoprotectant buffer. The crystals were cooled directly in the dinitrogen cryostream after soaking in fresh mother liquor containing 15-30\% (v/v) ethylene glycol (plus the appropriate agent) as a cryoprotectant for a few seconds. No suitable crystals were obtained from cocrystallization experiments with nitrite or arsenite. Nitrite and arsenite on soaking had a deleterious effect on the native crystals, giving highly anisotropic data to resolution of less than $3.0 \AA$. However, the nitrate soak and the cocrystallized nitrate, cyanide, azide, or perchlorate (including crystals from a perchlorate sample left at room temperature for several months) crystals did give suitable diffraction.

Attempts were also made to crystallize DdNapA under reducing condition. The protein was incubated, prior to crystallization trials, with dithionite, dithiothreitol (DTT), MV, tris(2-carboxyethyl)phosphine hydrochloride (TCEP), DTT and MV, or TCEP and MV. Some of these samples yielded crystals, but although their morphology looked adequate, their diffraction was invariably poor or nonexistent.

Further attempts to obtain DdNapA in the reduced state were performed in an anaerobic chamber under reducing conditions. The protein was purified under aerobic conditions, introduced into the anaerobic chamber, and preincubated with $10 \mathrm{mM}$ concentration of one of the reducing agents (MV dye or dithionite). Crystals of these reduced samples were grown at approximately $295 \mathrm{~K}$, with 6\% PEG 8K and $100 \mathrm{mM}$ MES, pH 6.0. Single crystals were obtained, which were very similar to the ones obtained aerobically [15]. Initial attempts to flash-cool the crystals in liquid dinitrogen (inside the chamber, in order to maintain the reducing conditions) were, however, unsuccessful. The crystals were destabilized and diffracted to less than $3-\AA$ resolution at the ESRF (Grenoble, France) and the diffraction data were very anisotropic, making it impossible to obtain a complete, usable dataset. We then attempted to transport the crystals under anaerobic conditions. This was performed by mounting the crystal on a nylon loop which was then covered with a quartz capillary, held by Plasticine to the base of the Hampton pin. However, these trials also yielded no diffraction. Owing to these difficulties, and to the lack of stability of the crystals in the reduced form, no further attempts were made to obtain the structure of the reduced state of the protein.

Diffraction data were collected at beamlines ID14-EH1, ID14-EH3, ID14-EH4, and ID23-EH1 at the ESRF (Grenoble, France) using either a Quantum 4 or a 315R CCD detector (ADSC). About $100^{\circ}-180^{\circ}$ of data were collected with a $\phi$ rotation, $\Delta \phi=1.0^{\circ}$, to give complete datasets for the data collected on the ID14 beamlines and 720 images for the single-wavelength anomalous diffraction data on ID23 (collected below, i.e., at a lower energy than, the iron edge with $\lambda=1.77 \AA$,) to give a highly redundant dataset (multiplicity 34.5). All data were processed using the programs MOSFLM and SCALA from the CCP4 suite [16-18]. The crystals belong to the trigonal space group $P 3_{1} 21$ with cell constants $105-106 \AA \times 105-106 \AA$ × 130-135 $\AA$, with a single molecule in the asymmetric unit. Although several datasets were obtained for each sample, only the best in terms of resolution and quality were used for further study (Table 1). The dataset labeled NITRATE is from a DdNapA sample which was first reduced with dithionite, then reacted with nitrate, and finally air-reoxidized. This sample had been dialyzed and concentrated before crystallization. Dataset NITRATE SOAK is from NITRATE crystals soaked with $10 \mathrm{mM} \mathrm{NaNO}$. Dataset PERCHLORATE is from crystals cocrystallized with perchlorate (dataset "old" with a sample left at room temperature for over 6 months as opposed to "fresh" for a sample cocrystallized straight after thawing from $193 \mathrm{~K}$ ). CYANIDE and AZIDE are data from the respective cocrystallizations and SAD is native data collected at a wavelength of $1.77 \AA$. All cocrystallized samples were prepared as the NITRATE sample and were in an air-oxidized state. Data collection and processing statistics for all datasets are given in Table 1.

Model building and refinement

The native structure of DdNapA (Protein Data Bank accession code 2NAP) was used to fit into each dataset after rigid-body refinement in REFMAC5 [19], treating each domain (domain I, amino acid residues 4-61, 464492, and 517-561; domain II, amino acid residues 62-135, 347-463, and 493-516; domain III, amino acid residues 134-346; and domain IV, amino acid residues 562-723) as a rigid body. The bis-MGD cofactor, the $[4 \mathrm{Fe}-4 \mathrm{~S}]$ cluster, and the water molecules were excluded from the initial 


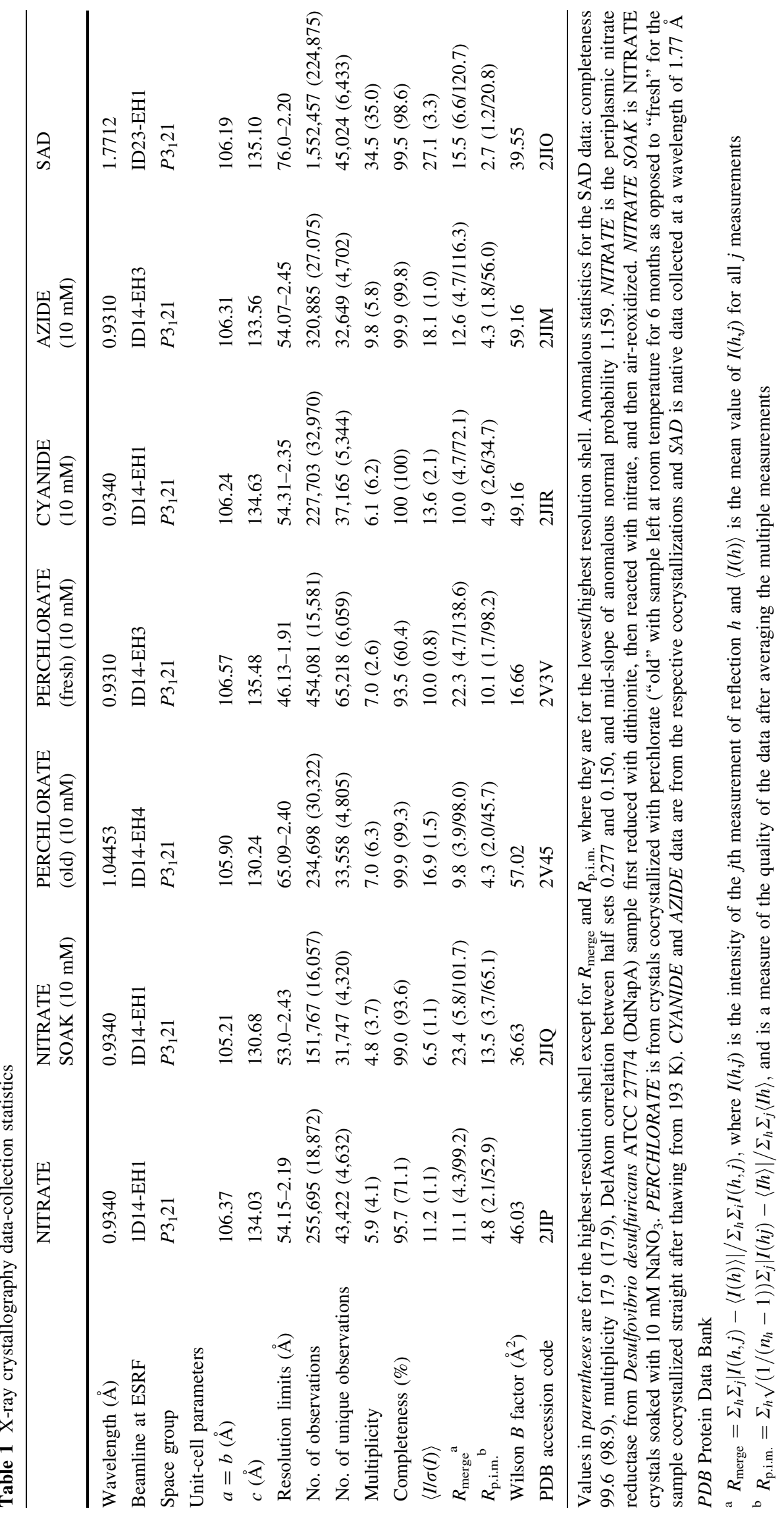


model. Iterative model building with O [20], and/or COOT [21], together with restrained refinement in REFMAC5 [19], initially, and then with restrained refinement including TLS (with each of the four domains treated as separate TLS entities) resulted in good final models (as judged by the validation tools in COOT [21]). These final models include amino acid residues 4-723 (with all the side chains), the catalytic molybdenum coordinated to two MGD cofactors, the $[4 \mathrm{Fe}-4 \mathrm{~S}]$ cluster, water molecules, and ligands in some cases. None of the above mentioned structures are thought to have the MES molecule in the solvent channel as reported in the original native structure (2NAP). There is no anomalous sulfur signal for it in the SAD structure. The first three residues of the N-terminus (Ala, Asp, and Asn) are disordered and were not included in the final models. Refinement statistics are presented in Table 2. The determination of the potential sixth coordinating ligand to the molybdenum atom was carried out towards the end of refinement. Initially, the sixth ligand was omitted from all the datasets. A clear positive peak was obtained in all the $\mathrm{mFo}-\mathrm{DFc}$ difference maps. Either a water molecule or a heavier atom such as sulfur atom was modeled in this density and then refined independently. For the CYANIDE data, a cyanide molecule, with either the nitrogen or the carbon atom binding the molybdenum atom, was also fitted into the density and refined.

For all datasets, no restraints were imposed on this sixth ligand. The $B$-factor analysis is shown in Table 3 .

Coordinates and observed structure factor amplitudes have been deposited in the Protein Data Bank under the accession codes 2JIP, 2JIQ, 2V45, 2V3V, 2JIR, 2JIM, and $2 \mathrm{JIO}$.

\section{Results and discussion}

X-ray crystallography studies

\section{Comparison of the crystal structures}

The comparison of the several DdNapA structures analyzed was carried out using ESCET [22, 23], a program that performs an all-pairwise error-scaled difference distance matrices calculation and then analyses them simultaneously using a genetic algorithm. The results are presented in Table 4 . The estimated standard deviations range from 0.15 to $0.32 \AA$ and the low root mean square deviation difference $(0.13-0.21 \AA)$ between the structures superposed on 2NAP (based on 646 out of $720 \mathrm{C} \alpha$ atoms) indicates that all the structures are highly similar with percentages greater than $98 \%$ for all but six pairs at $1 \sigma$ low threshold. About $90 \%$ of the DdNapA structure is in a conformationally invariant part. The 74 residues which show the highest variations are all on the protein surface and include loops and turns. Some of these have been assigned with alternative conformations.

\section{Analysis of the structures around the molybdenum active site and the sixth molybdenum ligand}

In the native oxidized DdNapA structure (2NAP) reported in 1999 [4], the Mo(VI) is coordinated by six ligands. Four of them are provided by the two dithiolene sulfur atoms from $\mathrm{MGD}_{811}$ and $\mathrm{MGD}_{812}$ and a fifth ligand is the $\mathrm{S} \gamma$ atom of $\mathrm{Cys}_{\mathrm{A} 140}$. The sixth ligand of molybdenum was then assigned to an $\mathrm{OH} / \mathrm{OH}_{2}$ on the basis of the refined bond

Table 2 Structure refinement

\begin{tabular}{|c|c|c|c|c|c|c|c|c|}
\hline & NITRATE & $\begin{array}{l}\text { NITRATE SOAK } \\
(10 \mathrm{mM})\end{array}$ & $\begin{array}{l}\text { PERCHLORATE } \\
\text { (old, } 10 \mathrm{mM} \text { ) }\end{array}$ & $\begin{array}{l}\text { PERCHLORATE } \\
\text { (fresh, } 10 \mathrm{mM} \text { ) }\end{array}$ & $\begin{array}{l}\text { CYANIDE } \\
(10 \mathrm{mM})\end{array}$ & $\begin{array}{l}\text { AZIDE } \\
(10 \mathrm{mM})\end{array}$ & $\begin{array}{l}\text { NATIVE } \\
\text { (SAD) }\end{array}$ & $\begin{array}{l}\text { 2NYA } \\
\mathrm{A} / \mathrm{F}\end{array}$ \\
\hline Resolution ( & 2.30 & 2.44 & 2.40 & 1.99 & 2.35 & 2.45 & 2.20 & 2.5 \\
\hline $\begin{array}{l}\text { Reflections } \\
\text { used }\end{array}$ & 37,838 & 30,226 & 31,783 & 57,324 & 35,628 & 31,238 & 42,713 & 53,973 \\
\hline$R_{\text {work }}^{\mathrm{a}}(\%)$ & 17.8 & 16.1 & 16.5 & 18.2 & 16.4 & 17.8 & 15.3 & 18.1 \\
\hline$R_{\text {free }}{ }^{\mathrm{b}}(\%)$ & 25.2 & 25.0 & 24.0 & 24.6 & 23.5 & 25.2 & 20.9 & 24.3 \\
\hline$R_{\text {map }}{ }^{\mathrm{c}}(\%)$ & 20.6 & 17.8 & 20.1 & 21.8 & 18.9 & 20.4 & 16.7 & - \\
\hline $\begin{array}{l}\text { Number of } \\
\text { waters }\end{array}$ & 620 & 752 & 520 & 757 & 670 & 450 & 810 & 1,134 \\
\hline $\begin{array}{l}\text { Number of } \\
\text { other ligands }\end{array}$ & 0 & 6 nitrate & 1 perchlorate & 4 perchlorate & 0 & 0 & 0 & 0 \\
\hline
\end{tabular}

2NYA refers to the data for the periplasmic nitrate reductase from Escherichia coli dimer from Jepson et al. [6]. The first value is for chain A and second for chain $\mathrm{F}$ in 2NYA

${ }^{\text {a }} R_{\text {work }}=\Sigma|| F_{\text {calc }}|-| F_{\text {obs }}|| / \Sigma\left|F_{\text {obs }}\right| \times 100$, where $F_{\text {calc }}$ and $F_{\text {obs }}$ are the calculated and observed structure factor amplitudes, respectively

${ }^{\mathrm{b}} \mathrm{R}_{\text {free }}$ is calculated for a randomly chosen $5 \%$ of the reflections for each dataset

${ }^{\mathrm{c}} R_{\text {map }}$ is the $R$ factor for the map calculated by the EDS server (http://eds.bmc.uu.se/eds) for the final PDB coordinates 
Table 3 The sixth ligand of molybdenum $B$-factor analysis $\left(\AA^{2}\right)$

\begin{tabular}{|c|c|c|c|c|c|c|c|c|}
\hline & NITRATE & $\begin{array}{l}\text { NITRATE } \\
\text { SOAK } \\
(10 \mathrm{mM})\end{array}$ & $\begin{array}{l}\text { PERCHLORATE } \\
\text { (old, } 10 \mathrm{mM} \text { ) }\end{array}$ & $\begin{array}{l}\text { PERCHLORATE } \\
\text { (fresh, } 10 \mathrm{mM} \text { ) }\end{array}$ & $\begin{array}{l}\text { CYANIDE } \\
(10 \mathrm{mM})\end{array}$ & $\begin{array}{l}\text { AZIDE } \\
(10 \mathrm{mM})\end{array}$ & $\begin{array}{l}\text { NATIVE } \\
\text { (SAD) }\end{array}$ & $\begin{array}{l}\text { 2NYA } \\
\mathrm{A} / \mathrm{F}\end{array}$ \\
\hline Wilson $B$ factor $\left(\AA^{2}\right)$ & 46.03 & 36.63 & 57.02 & 29.76 & 49.16 & 59.16 & 39.55 & - \\
\hline $4 \mathrm{Fe} 4 \mathrm{~S}_{800}$ range & $43.4-51.5$ & $25.5-30.0$ & $41.9-46.9$ & $14.8-18.0$ & $36.8-40.6$ & $37.9-45.5$ & $30.9-40.3$ & $25.5-30.3 / 24.1-28.1$ \\
\hline $\mathrm{S} \delta \mathrm{Met}_{\mathrm{A} 308}$ & 39.8 & 15.7 & 52.7 & 9.3 & 38.8 & 46.6 & 28.1 & $21.2 / 21.0$ \\
\hline $\mathrm{S} \gamma \mathrm{Cys}_{\mathrm{A} 307}$ & 37.1 & 21.0 & 51.1 & 15.0 & 38.1 & 39.1 & 32.2 & $20.1 / 18.4$ \\
\hline $\mathrm{S} 12 \mathrm{MGD}_{811}$ & 38.7 & 25.5 & 43.2 & 13.2 & 36.9 & 36.1 & 32.2 & $20.2 / 21.4$ \\
\hline S13 $\mathrm{MGD}_{811}$ & 34.0 & 20.7 & 39.8 & 10.0 & 33.5 & 33.0 & 28.1 & $19.2 / 22.3$ \\
\hline $\mathrm{S} 12 \mathrm{MGD}_{812}$ & 40.6 & 28.6 & 46.3 & 11.1 & 37.4 & 40.6 & 25.2 & $21.1 / 24.4$ \\
\hline S13 $\mathrm{MGD}_{812}$ & 46.8 & 20.6 & 47.9 & 16.5 & 39.7 & 45.8 & 29.8 & $13.3 / 21.4$ \\
\hline $\mathrm{S} \delta \mathrm{Met}_{\mathrm{A} 141}$ & 43.3 & 23.5 & 56.1 & 15.1 & 40.4 & 45.1 & 30.0 & $20.2 / 25.6$ \\
\hline $\mathrm{S} \gamma \mathrm{Cys}_{\mathrm{A} 140}$ & 42.4 & 24.0 & 53.1 & 14.5 & 43.2 & 40.6 & 33.6 & $20.2 / 25.6$ \\
\hline Mo & 41.5 & 25.1 & 46.3 & 15.4 & 39.8 & 42.6 & 29.6 & $20.3 / 24.4$ \\
\hline Peak height $^{\mathrm{a}}$ & $14.3 \sigma$ & $11.5 \sigma$ & $11.0 \sigma$ & $16.0 \sigma$ & $11.2 \sigma$ & $10.6 \sigma$ & $17.3 \sigma$ & $\sim 6 \sigma$ \\
\hline $\mathrm{S}_{813}(75 \%)$ & 38.3 & 25.6 & 49.8 & 16.0 & $52.8(42.1)$ & 45.9 & 25.3 & - \\
\hline $\mathrm{HOH}$ & 18.9 & 3.49 & 27.7 & 2.0 & 29.2 & 22.9 & 7.51 & $5.86 / 2.0$ \\
\hline $\mathrm{C} / \mathrm{N}(-\mathrm{Mo})$ & & & & & $32.3 / 37.6$ & & & - \\
\hline N/C (-Mo) & & & & & $29.7 / 39.6$ & & & \\
\hline
\end{tabular}

Met $_{A 308}, C y s_{A 307}, M_{e t} t_{A 141}$, and $C y s_{A 140}$ correspond to $\mathrm{Met}_{336}, \mathrm{Thr}_{335}, \mathrm{Met}_{144}$, and $\mathrm{Cys}_{143}$ in 2NYA, respectively

$M G D$ molybdopterin guanosine dinucleotide

${ }^{a}$ The peak height obtained in the omit $\mathrm{mFo}-\mathrm{DFc}$ difference electron density maps when the sixth ligand is excluded

Table 4 Structural comparison of DdNapA using ESCET [22, 23], an error-scaled difference distance matrix method

\begin{tabular}{|c|c|c|c|c|c|c|c|c|}
\hline & $2 \mathrm{NAP}$ & $\begin{array}{l}\text { NITRA } \\
\text { TE }\end{array}$ & $\begin{array}{l}\text { NITRATE } \\
\text { SOAK }\end{array}$ & $\begin{array}{c}\text { PERC } \\
\text { HLOR } \\
\text { ATE } \\
\text { old }\end{array}$ & $\begin{array}{c}\text { PERC } \\
\text { HLOR } \\
\text { ATE } \\
\text { fresh }\end{array}$ & CYANIDE & AZIDE & SAD \\
\hline${ }^{*}$ LSQ Fit $[\AA]$ & 0.0 & 0.170 & 0.207 & 0.197 & 0.177 & 0.159 & 0.191 & 0.130 \\
\hline$\langle\operatorname{esd}>[\AA \AA]$ & 0.15 & 0.24 & 0.28 & 0.32 & 0.16 & 0.25 & 0.28 & 0.17 \\
\hline & & & & & & & & \\
\hline 2NAP & - & 98.6 & 97.8 & 98.6 & 91.8 & 99.1 & 97.7 & 98.2 \\
\hline NITRATE & 95.4 & 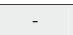 & 98.5 & 99.4 & 95.6 & 99.7 & 99.4 & 98.5 \\
\hline $\begin{array}{l}\text { NITRATE } \\
\text { SOAK }\end{array}$ & 93.0 & 95.1 & - & 99.9 & 98.4 & 99.1 & 99.6 & 98.6 \\
\hline $\begin{array}{l}\text { PERCHLOR } \\
\text { ATE old }\end{array}$ & - & - & - & - & 99.2 & 99.5 & 99.9 & 99.1 \\
\hline $\begin{array}{l}\text { PERCHLOR } \\
\text { ATE fresh }\end{array}$ & 82.2 & 89.3 & 94.9 & - & - & 96.5 & 98.9 & 94.4 \\
\hline CYANIDE & 96.7 & 97.2 & 96.9 & - & 91.8 & - & 99.5 & 99.1 \\
\hline AZIDE & 93.4 & 96.6 & 98.0 & - & 97.6 & 97.8 & - & 98.7 \\
\hline SAD & 95.4 & 95.5 & 95.1 & - & 88.1 & 97.2 & 95.5 & \\
\hline
\end{tabular}

Percentages smaller than $1 \sigma$ for all pairwise comparisons are given in the part above the shaded diagonal and those smaller than $0.75 \sigma$ are given in the part below the shaded diagonal. PERCHLORATE (old) was excluded from this analysis as it is the most similar to all the other models, i.e., with percentages greater than $98 \%$ in the first analysis. The values for the structures which have the largest differences between themselves are boxed

2NAP native structure of DdNapA

* LSQ fit superpositioning of each structure on $2 \mathrm{NAP}$ based on 646 out of $720 \mathrm{C} \alpha$ atoms [17]

$\langle e s d\rangle$ estimated standard deviation from mean atomic position distance for Mo-O (approximately $2.1 \AA$ ), although residual electron density close to the $\mathrm{OH}$ ligand was then not interpreted [4].

The thorough analysis and high quality of the diffraction data reported in this study allowed the interpretation of the extra electron density at the molybdenum coordination sphere, which strongly suggested a heavier atom, possibly a sulfur atom. To test this hypothesis, a highly redundant dataset (multiplicity 35 for all the data, 17.9 for anomalous data) was collected at the ESRF below the iron edge $(\lambda=1.77 \AA$ ) to $2.2-\AA$ resolution (dataset SAD in Table 1$)$. These data allowed location of the sulfur, phosphorus, and molybdenum single-wavelength anomalous diffraction signals. The majority of the sulfurs have clearly defined anomalous signals, including the ones binding the [4Fe-4S] cluster. All the cysteinyl sulfurs, 13 out of 19 methionyl sulfurs, the four from the $[4 \mathrm{Fe}-4 \mathrm{~S}]$ cluster, and the four phosphorous atoms (two from each MGD cofactor) have an anomalous signal greater than $4 \sigma$. However, the molybdenum atom (with an anomalous peak of approximately $30 \sigma$ ) seems to have a damping effect on the anomalous signals of the sulfur atoms immediately coordinated to it. This effect is probably a combination of the large difference in $f^{\prime \prime}$ for the two elements (molybdenum and sulfur) at this wavelength $\left(1.77 \AA\right.$, approximately $7 \mathrm{keV}, f^{\prime \prime}{ }_{\text {Mo }}=3.48$; $\left.f^{\prime \prime}{ }_{\mathrm{S}}=0.72\right)$ with the nominal data resolution of $2.2 \AA$. Nevertheless, the shape of the anomalous electron density 
strongly suggests that the molybdenum sixth coordination position is occupied by a second-row atom (chlorine, sulfur, or phosphorous) and not by a lighter atom like oxygen $(\mathrm{OH} /$ $\mathrm{OH}_{2}$ ) as formerly proposed (Fig. 1a). The K-edge for chlorine, sulfur, and phosphorous is 4.40, 5.01, and $5.75 \AA$, respectively, so all of these should give a discernible anomalous signal at a wavelength of $1.77 \AA$.

Further assignment of the sixth ligand was done on the basis of the refinement and analysis of the $B$ factors since, generally, atoms bonded together have very similar $B$ factors and occupancies. From the refinement and analysis of the $B$ factors of all the structures (Table 3 ) together with EPR data, the sixth ligand could thus be assigned as a sulfur atom, as explained below.

All the datasets gave a peak greater than $10 \sigma$ in $\mathrm{mFo}-$ DFc difference electron density maps when the sixth ligand was omitted (Fig. 1, Table 3). For the NITRATE, PERCHLORATE (fresh), and SAD data, when the sixth molybdenum ligand was refined as an oxygen atom (water), a positive peak (greater than $3 \sigma$ ) was present in mFo-DFc maps (Figs. 2, 3). In addition, the $B$ factors for an oxygen ligand were consistently much smaller than those from surrounding atoms as detailed in Table 3 for all data sets (12-60\% of that from molybdenum). For six of the seven datasets, the $B$ factors are invariably more in agreement with there being a sulfur atom at the sixth coordination position than an oxygen atom. When the sixth ligand was refined as a sulfur atom, the corresponding temperature factors were of similar magnitude to those of the surrounding atoms and the extra electron density disappeared in the final mFo-DFc maps (Figs. 2, 3). For the SAD and PERCHLORATE data, the sixth ligand was also refined as either chlorine or phosphorous. As expected, chlorine gives slightly higher $B$ factors and phosphorous slightly lower ones (for $\mathrm{SAD}$ data the $B$ factors were $27.1 \AA^{2}$ for $\mathrm{Cl}$ and $22.9 \AA^{2}$ for $\mathrm{P}$, cf. $25.3 \AA^{2}$ for $\mathrm{S}$ and $29.6 \AA^{2}$ for molybdenum; for PERCHLORATE data the $B$ factors were $18.6 \AA^{2}$ for $\mathrm{Cl}$ and $14.1 \AA^{2}$ for $\mathrm{P}$, cf. $16.0 \AA^{2}$ for $\mathrm{S}$ and $15.4 \AA^{2}$ for molybdenum).

In contrast to the sulfur nucleus $\left(I=0\right.$ for ${ }^{32} \mathrm{~S}, 95 \%$ abundance), the naturally occurring isotopes of chlorine and phosphorous have nonzero nuclear spins $(I=3 / 2$,
Fig. 1 Molybdenum active site, including the two molybdopterin guanosine dinucleotides, $\mathrm{Cys}_{\mathrm{A} 140}$ (molybdenum ligand), $\mathrm{Met}_{\mathrm{A} 141}$, and $\mathrm{Met}_{\mathrm{A} 308}$. a Stereo view of the anomalous electron density map contoured at $3 \sigma$ for the SAD dataset. b Stereo views of the $2 \mathrm{mFo}-\mathrm{DFc}$ electron density maps (blue) contoured at $1 \sigma$ calculated using the final refined model, with sulfur ( $R$ factor of $15.0 \%$ and $R_{\text {free }}=20.9 \%$ ) in the top panel and with water as the sixth ligand in the bottom panel. Comparison of the $\mathrm{mFo}-$ DFc maps (contoured at $3 \sigma$ ) calculated from the refinement using a sulfur (top) or a water molecule (bottom) shows a positive peak (red) around the water molecule that is not observed in the sulfurcontaining refinement. This suggests that sulfur is the sixth ligand of the molybdenum (pink). Also, this ligand, when refined as a sulfur atom, has a $B$ factor of approximately $25 \AA^{2}$ (similar to the surrounding atoms), whereas when it was refined as an oxygen atom it had a $B$ factor of approximately $7.5 \AA^{2}$. This figure and Figs. 2, 3,4 , and 6 were made using PyMOL [49]
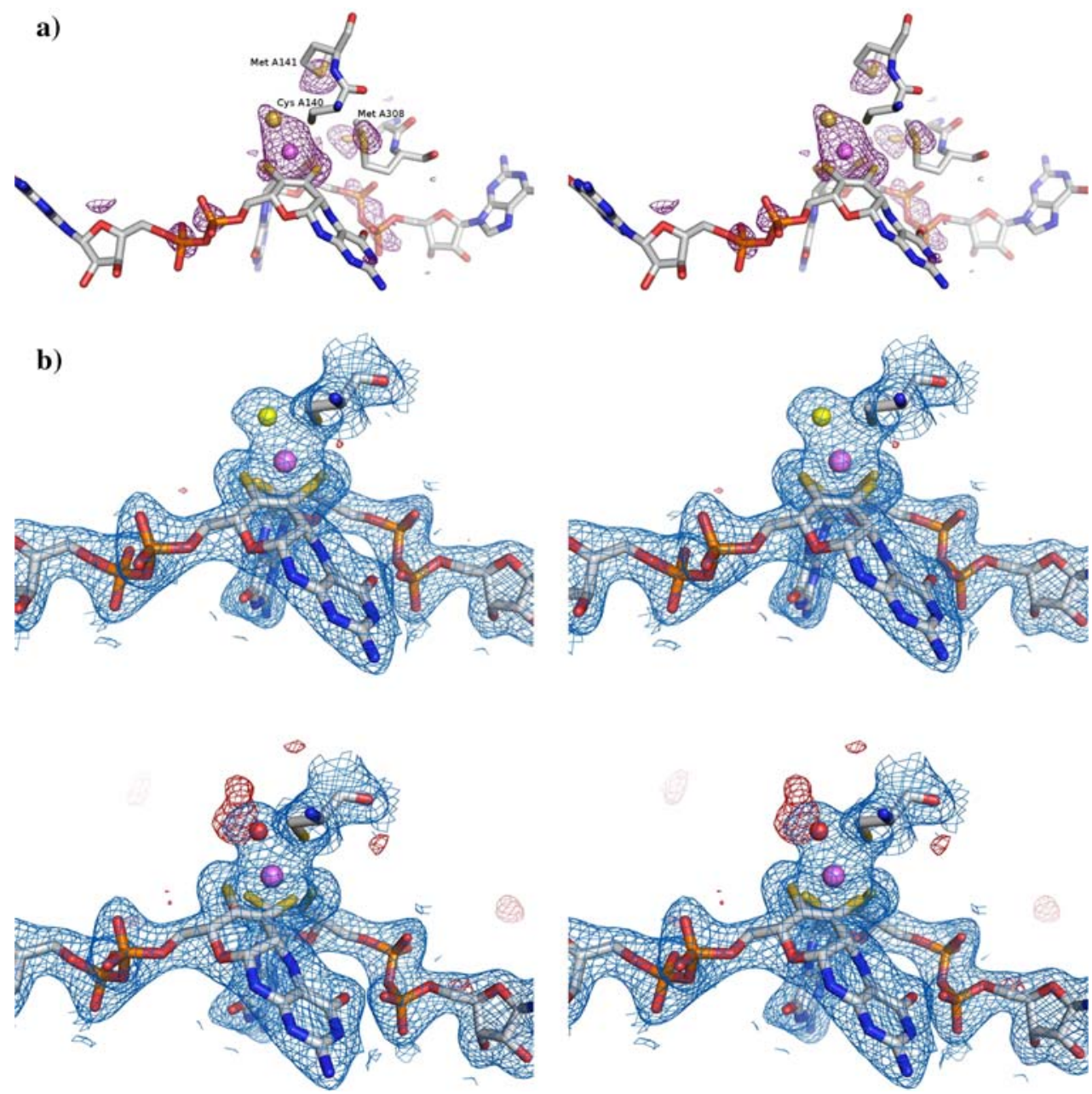
Fig. 2 Gallery of the molybdenum active sites for four of the structures analyzed. a SAD, b NITRATE,

c PERCHLORATE, and d CYANIDE, The $2 \mathrm{mFo}-\mathrm{DFc}$ electron density maps contoured at $1 \sigma$ (blue) and the $\mathrm{mFo}-\mathrm{DFc}$ electron density maps contoured at $3 \sigma$ (red) calculated in the absence of a sixth ligand (left) and calculated in the presence of the sulfur atom in the final refinement (right) a)

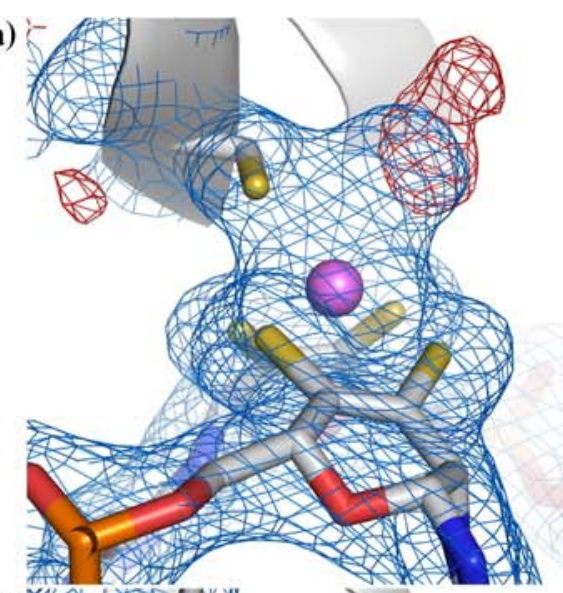

b)

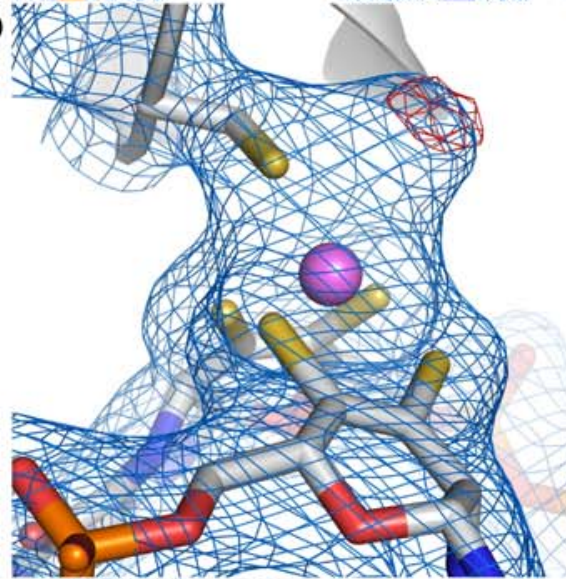

c)

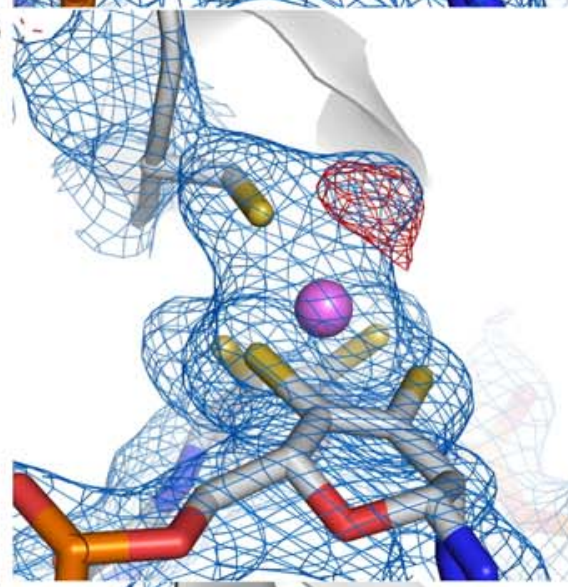

d)

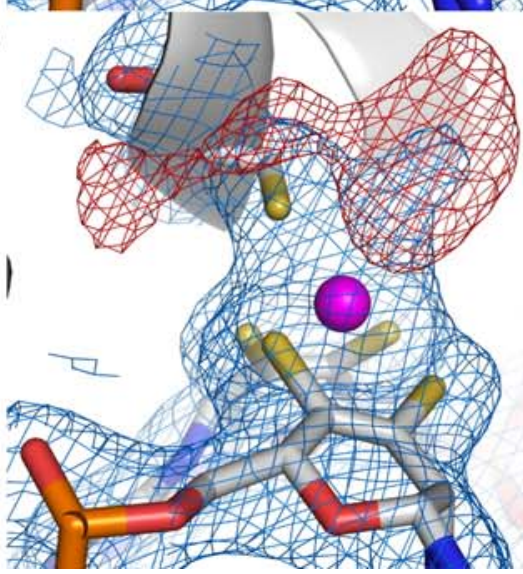

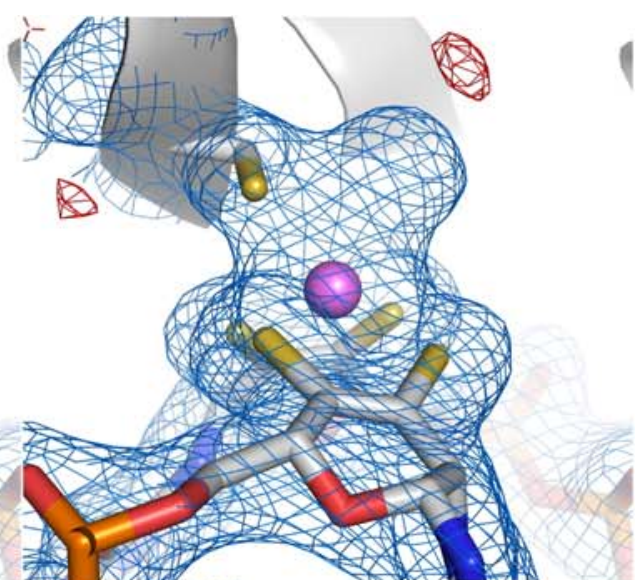
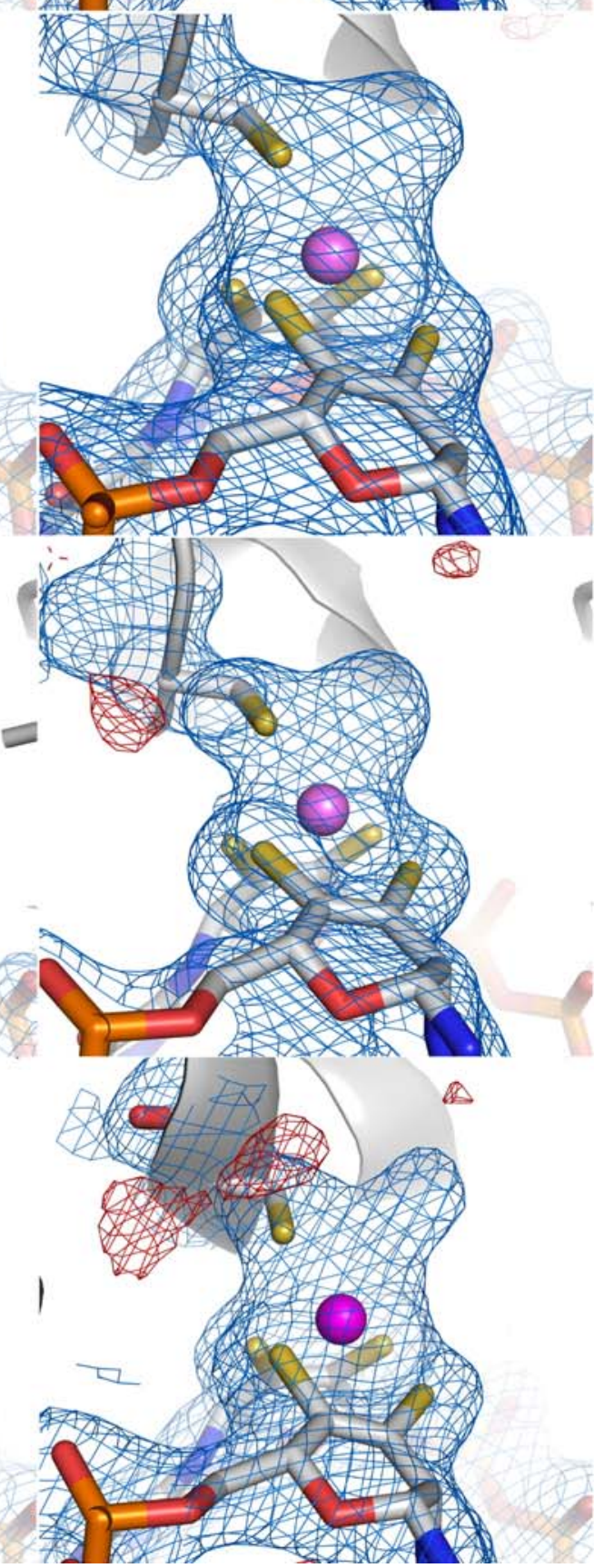
Fig. 3 Details of the molybdenum active site [PERCHLORATE (fresh) $2 \mathrm{mFo}-\mathrm{DFc}]$ as in Fig. 2c, but in a different orientation, highlighting the shorter distance between the sulfur $\left(S_{813}\right.$, yellow) and the $\mathrm{S} \gamma$ of $\mathrm{Cys}_{\mathrm{A} 140}$ $(2.40 \AA)$ compared with the distance between the dithiolene sulfur atoms (3.04 ̊). Met $_{\mathrm{A} 308}$ is visible on the left of the active site, with a distance of $3.90 \AA$ from the $\mathrm{S} \gamma$ atom of $\mathrm{Cys}_{\mathrm{A} 140}$

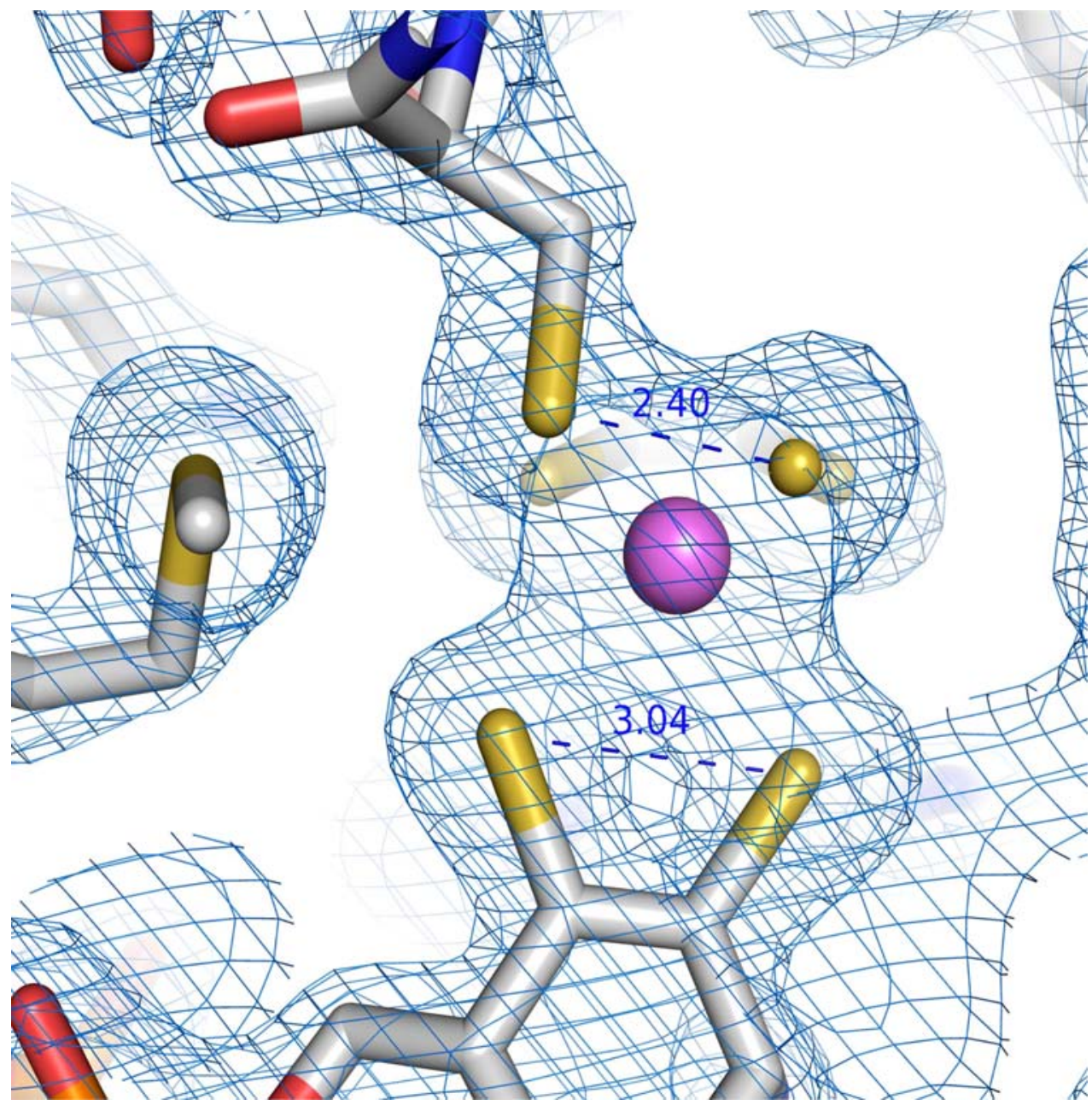

$g_{\mathrm{n}} \sim 0.5$ for ${ }^{35,37} \mathrm{Cl}$ and $I=1 / 2, g_{\mathrm{n}}=2.26$ for ${ }^{31} \mathrm{P}$ ) and hence superhyperfine structure from these nuclei might be observed in the EPR spectra associated with Mo(V) species. Hyperfine couplings associated with chloride nuclei in equatorial positions have been reported in model complexes of $\mathrm{Mo}(\mathrm{V})$ ions in nearly octahedral or squarepyramidal coordination [24] and in the molybdenum enzyme sulfite oxidase [25]. Larger couplings should be expected for the phosphorous atom because of the higher nuclear $g$ factor $\left(g_{\mathrm{n}}=2.26\right)$. Therefore, the lack of detection of superhyperfine structure attributable to any of these nuclei suggests that the sixth position is occupied by a sulfur atom. In line with this observation, electron-nuclear double resonance studies in the closely related Nap from $P$. pantotrophus do not reveal any hyperfine coupling with either chlorine or phosphorous nuclei, which gives additional support to our assumption [10].

The crystallographic data from EcNapA (Protein Data Bank accession code 2NYA) [6] as shown in Table 3 also favor a sulfur atom for the sixth ligand. Additional evidence comes from the related Cupriavidus necator $\mathrm{H} 16$ NapAB structure refined to $1.5 \AA$ (unpublished data, [26]), which showed identical results; that is, the large difference in the relative $B$ factors between the molybdenum and the hydroxyl ligand was corrected when the refinement was carried out with a sulfur ligand at the sixth coordination position.

Another unexpected result was that, for all the datasets, the distances between the sulfur ligand and the $\mathrm{S} \gamma$ atom of $\mathrm{Cys}_{\mathrm{A} 140}$ are substantially shorter than the van der Waals contact distance (approximately $3.3 \AA$ ), varying from $2.17 \AA$ for the NITRATE dataset to $2.85 \AA$ for the AZIDE dataset (Table 5). The angle $\mathrm{S}-\mathrm{Mo}-\mathrm{S} \gamma$, which ranges from $55^{\circ}$ to $74^{\circ}$, indicates a clear distortion from the molybdenum octahedral coordination geometry, compared with the range of angles of $74^{\circ}-83^{\circ}$ for the S12-Mo-S13 angle for both of the MGD cofactors. These facts are indicative of a partial bond between the thiolate of $\mathrm{Cys}_{\mathrm{A} 140}$ and the sulfido ligand. The shape of the anomalous density in the SAD data also adds support to this observation (Fig. 1).

This is the first experimental evidence of a partial S-S bond for a mononuclear molybdenum enzyme. An analogous conclusion was derived from extended X-ray absorption fine structure (EXAFS) studies performed on 
the closely related EcFdh-H [27] and Fdh from D. desulfuricans ATCC 27774 [28], but assuming a partial Se-S bond in the molybdenum site. Both enzymes show hexacoordinated molybdenum sites comparable to those of Nap, but with a selenium atom from a selenocysteine instead of a Cys $\mathbf{S} \gamma$. At that time, the sixth position was modeled as an oxygen atom on the basis of EXAFS studies. Therefore, an unexpected $\mathrm{Se}-\mathrm{S}$ bond was proposed, involving a triangular arrangement of molybdenum, selenium, and a sulfur atom from one of the pterin moieties [27, 28]. A recent reanalysis of the structural data of EcFdh-H confirmed the presence of a sulfur atom in the sixth ligand position [8]. In this case the result could be better explained with a partial $\mathrm{Se}-\mathrm{S}$ bond involving the sulfido ligand similar to the result reported here.

\section{Guiding the nitrate to the active site}

To test the localization of the nitrate ions along the funnellike channel leading to the molybdenum active site, single crystals of DdNapA were soaked with a nitrate ion solution (see "Materials and methods" for details). The corresponding crystal structure (NITRATE SOAK) was solved to $2.44-\AA$ resolution. Though no differences are observed at the molybdenum site with respect to the as-prepared sample, it was possible to model six nitrate ions on the basis of electron density to be bound at the entrance of the funnel leading to the molybdenum atom (Fig. 4). The amino acid residues involved in guiding the nitrate substrate to the catalytic site at the end of the funnel include $\operatorname{Arg}_{\mathrm{A} 138}$, $\operatorname{Arg}_{\mathrm{A} 354}, \mathrm{Ser}_{\mathrm{A} 360}, \mathrm{His}_{\mathrm{A} 396}, \mathrm{Tyr}_{\mathrm{A} 533}$, and $\operatorname{Arg}_{\mathrm{A} 709}$, showing that the interactions between nitrate and the residues of the funnel are due to electrostatic forces and hydrogen-bonding interactions. The funnel narrows to a gap of about $3 \AA \times 5 \AA$ as it gets closer to the active site, with residues $\mathrm{Met}_{\mathrm{A} 141}, \mathrm{Pro}_{\mathrm{A} 137}$, and $\mathrm{Ala}_{\mathrm{A} 349}$ providing the wall. Thus, the planar nitrate ion would only be able to reach the catalytic site sideways, as shown by the dotted modeled nitrate ions in Fig. 4.

\section{Structures of inhibited forms}

Previous studies showed that cyanide, azide, and perchlorate are inhibitors of DdNapA [9, 29, 30]. Furthermore, cyanide-reacted samples (see "Materials and methods" for details) show a nearly axial EPR signal (less than 0.1 spin per molecule) (Fig. 5, spectrum d), suggesting a different structure for the molybdenum site with respect to the hexacoordinated molybdenum site of the as-prepared form. This does not happen for the azide- and perchlorate-inhibited samples, in which no EPR signals could be detected.

To get some insight into the inhibition mechanisms and to establish the reasons for the different EPR behavior of the different inhibited forms, $\mathrm{X}$-ray studies were carried out with crystals prepared from the EPR samples as explained in "Materials and methods." The PERCHLORATE data extend to 1.91- $\AA$ resolution but the structure was refined to $1.99 \AA$. These are the best data collected to date for a DdNapA inhibited sample in terms of resolution and quality. A large positive $\mathrm{mFo}-\mathrm{DFc}$ peak $[14 \sigma$ for PERCHLORATE (fresh) and $17 \sigma$ for PERCHLORATE (old)] is present in the funnel cavity blocking the pathway from the surface to the molybdenum active site (Fig. 6). A perchlorate ion could be modeled reasonably well in this isotropic electron density. It is trapped between $\operatorname{Pro}_{\mathrm{A} 137}$, $\operatorname{Arg}_{\mathrm{A} 138}, \mathrm{Met}_{\mathrm{A} 141}, \mathrm{Ala}_{\mathrm{A} 142}, \mathrm{Val}_{\mathrm{A} 145}, \operatorname{Arg}_{\mathrm{A} 354}$, and Leu $\mathrm{Lu}_{\mathrm{A} 359}$. All these residues are highly conserved in NRs, with the exception of $\mathrm{Leu}_{\mathrm{A} 359}$ and $\mathrm{Pro}_{\mathrm{A} 137}$, which are, in some cases, replaced by Phe and Ala, respectively. Perchlorate ions cannot enter deeper into this cavity because they are too bulky. The inhibition mechanism would thus take place by blocking the entry of the substrate to the catalytic site, some $10 \AA$ away from the molybdenum atom. In contrast, a planar nitrate ion would be able to get through the cavity between $\operatorname{Pro}_{\mathrm{A} 137}$, $\mathrm{Met}_{\mathrm{A} 141}$, and $\mathrm{Ala}_{\mathrm{A} 349}$ (also conserved) all the way to the catalytic site (Fig. 4). Three more perchlorate ions can be modeled with partial occupancy in the funnel. They have omit-map peak heights of $7.9 \sigma, 7.8 \sigma$, and $7.8 \sigma$ in the PERCHLORATE (fresh) structure.

The structures from cyanide- and azide-inhibited DdNapA samples were solved to 2.35 - and 2.45 - $\AA$ resolution, respectively. For the CYANIDE data the refinement of the sixth ligand as a sulfur atom was not as clear as for the other datasets, which may be due to the inhibitory effect of cyanide. In this case it was possible to model either a cyanide ion (with either the nitrogen or the carbon atoms coordinating the molybdenum atom) or a sulfur atom with $75 \%$ occupancy giving rise to a better $B$ factor correlation. EPR data taken with labeled cyanide $\left(\mathrm{KC}^{15} \mathrm{~N}, I_{\mathrm{N}}=1 / 2\right.$; $\mathrm{K}^{13} \mathrm{CN}, I_{\mathrm{C}}=1 / 2$ ) do not show hyperfine splitting associated with either nitrogen or carbon, which suggests that a cyanide molecule is not coordinated to molybdenum, at least in the EPR-active species [9]. In this context, the results of the refinement for the CYANIDE dataset could be due to a mixture of different forms probably related to the reactivity of the sulfur ligand, suggesting that inhibition by cyanide occurs by cyanolysis of the sulfur ligand in the sixth position in analogy to the cyanolysable sulfido group in xanthine oxidase [31]. This result is, however, in contrast with steady-state kinetic studies in Nap from other sources, which show that the cyanide behaves as a reversible inhibitor, and with EPR data of Nap samples reacted with cyanide, which showed that the nearly axial $\mathrm{Mo}(\mathrm{V})$ signal shown in Fig. 5, spectrum d disappears after dialysis against cyanide-free buffer $[9,10]$. These results are contradictory and need additional experimental work. 
Table 5 Geometry analysis: bonding distances and angles for the Mo and $\mathrm{S} \gamma$-Cys $\mathrm{A}_{\mathrm{A} 40}$ atoms to their corresponding ligands

\begin{tabular}{|c|c|c|c|c|c|c|c|c|c|}
\hline & 2NAP & NITRATE & $\begin{array}{l}\text { NITRATE } \\
\text { SOAK }\end{array}$ & $\begin{array}{l}\text { PERCHLORATE } \\
\text { (old) }\end{array}$ & $\begin{array}{l}\text { PERCHLORATE } \\
\text { (fresh) }\end{array}$ & $\begin{array}{l}\text { CYANIDE } \\
(\mathrm{S} \text { at } 75 \%)\end{array}$ & AZIDE & SAD & $\begin{array}{l}2 \mathrm{NYA} \\
\mathrm{A} / \mathrm{F}\end{array}$ \\
\hline \multicolumn{10}{|c|}{ Distance from $\operatorname{Mo}_{810}(\AA)$} \\
\hline S12 $\mathrm{MGD}_{811}$ & 2.36 & 2.25 & 2.40 & 2.33 & 2.21 & 2.38 & 2.37 & 2.43 & $2.27 / 2.27$ \\
\hline S13 MGD 811 & 2.19 & 2.27 & 2.49 & 2.38 & 2.43 & 2.31 & 2.07 & 2.40 & $2.41 / 2.29$ \\
\hline $\mathrm{S} 12 \mathrm{MGD}_{812}$ & 2.40 & 2.39 & 2.37 & 2.44 & 2.42 & 2.45 & 2.41 & 2.48 & $2.40 / 2.57$ \\
\hline S13 MGD $_{812}$ & 2.39 & 2.42 & 2.32 & 2.35 & 2.33 & 2.47 & 2.34 & 2.46 & $2.49 / 2.45$ \\
\hline $\mathrm{S} \gamma \mathrm{Cys}_{\mathrm{A} 140}$ & 2.59 & 2.17 & 2.26 & 2.18 & 2.40 & 2.55 & 2.44 & 2.34 & $2.49 / 2.31$ \\
\hline $\mathrm{S}_{813^{\mathrm{a}}}$ & 2.06 & 2.31 & 2.52 & 2.56 & 2.32 & 2.56 & 2.30 & 2.25 & $2.50 / 2.42$ \\
\hline $\begin{array}{l}\mathrm{S}_{813}-\mathrm{Mo}-\mathrm{S} \gamma \\
\mathrm{Cys}_{\mathrm{A} 140} \text { angle }\left({ }^{\circ}\right)\end{array}$ & 55.2 & 58.1 & 58.3 & 61.8 & 66.2 & 65.2 & 73.9 & 62.5 & $68.3 / 73.7$ \\
\hline $\begin{array}{l}\text { S12-Mo-S13 angle } \\
\left({ }^{\circ}\right) \text {, for each } \\
\text { MGD }\end{array}$ & $76.4,78.5$ & $79.2,78.8$ & $77.1,79.2$ & $79.0,82.4$ & $79.1,81.6$ & $76.8,74.3$ & $77.3,82.8$ & 79.7, 79.8 & $\begin{array}{c}79.8,78.7 / \\
75.7 \\
76.5\end{array}$ \\
\hline \multicolumn{10}{|c|}{ Distance from $\mathrm{S} \gamma \mathrm{Cys}_{\mathrm{A} 140}(\AA)$} \\
\hline $\mathrm{S}_{813}(\mathrm{~S}-\mathrm{S})^{\mathrm{a}}$ & 2.28 & 2.17 & 2.37 & 2.45 & 2.44 & 2.56 & 2.85 & 2.36 & $2.81 / 2.84$ \\
\hline $\mathrm{S} \delta \mathrm{Met}_{\mathrm{A} 308}$ & 3.64 & 3.81 & 3.90 & 3.66 & 3.61 & 3.93 & 3.78 & 3.54 & $3.51 / 3.58$ \\
\hline $\mathrm{S} \delta \mathrm{Met}_{\mathrm{A} 141}$ & 3.37 & 3.80 & 4.01 & 3.82 & 3.55 & 3.70 & 3.47 & 3.74 & $3.50 / 3.62$ \\
\hline
\end{tabular}

${ }^{\mathrm{a}}$ In the 2NAP and 2NYA PDB structures, $\mathrm{S}_{813}$ is modeled as an $\mathrm{HOH}$ atom. $\mathrm{Met}_{\mathrm{A} 308}, \mathrm{Met}_{\mathrm{A} 141}$, and $\mathrm{Cys}_{\mathrm{A} 140}$ in $2 \mathrm{NAP}$ correspond to Met $_{336}$, $\mathrm{Met}_{144}$ and $\mathrm{Cys}_{143}$ in 2NYA. For the CYANIDE data the distances and angles are for sulfur $\mathrm{S}_{813}$ with $75 \%$ partial occupancy

Fig. 4 Closeup of the area of the funnel leading to the active site of the NITRATE SOAK periplasmic nitrate reductase from Desulfovibrio desulfuricans ATCC 27774 (DdNapA). The solventaccessible funnel is depicted as a gray surface, showing four of the six nitrate ions identified in the electron density. The two hypothetical nitrate ions (dotted surfaces) close to the active site are represented only to show the accessibility to the active site. The upper modeled nitrate occupies the same space as the perchlorate. The lower modeled nitrate is fitted in the active-site cavity and is shown partially bonded to the $S_{813}$ atom

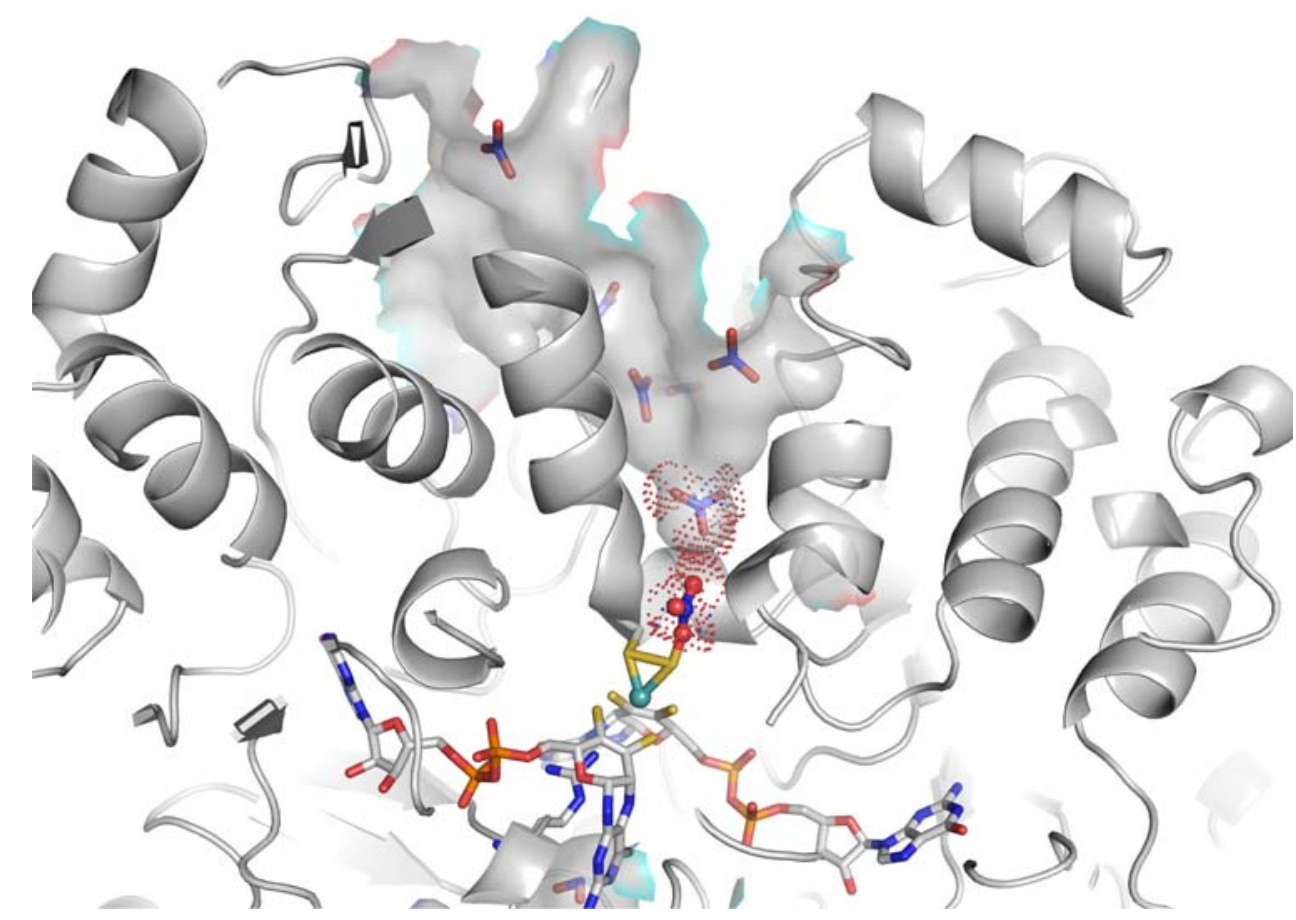

The AZIDE dataset also supports the presence of the sulfur atom at the sixth position, but no azide ions were found in these crystals. This is in line with the EPR data, which showed no significant changes with respect to the EPR spectra of the as-prepared proteins in reducing conditions. Further work is necessary to understand the structural basis of the inhibition by azide.
Optimizing the conditions to obtain the turnover signal: a MV-mediated redox titration

As reported by Gonzalez et al. [9], the addition to DdNapA of reduced MV, the electron donor used in the kinetic assay, followed by nitrate addition yields a rhombic EPR spectrum, which was called "turnover signal" (Fig. 5, 


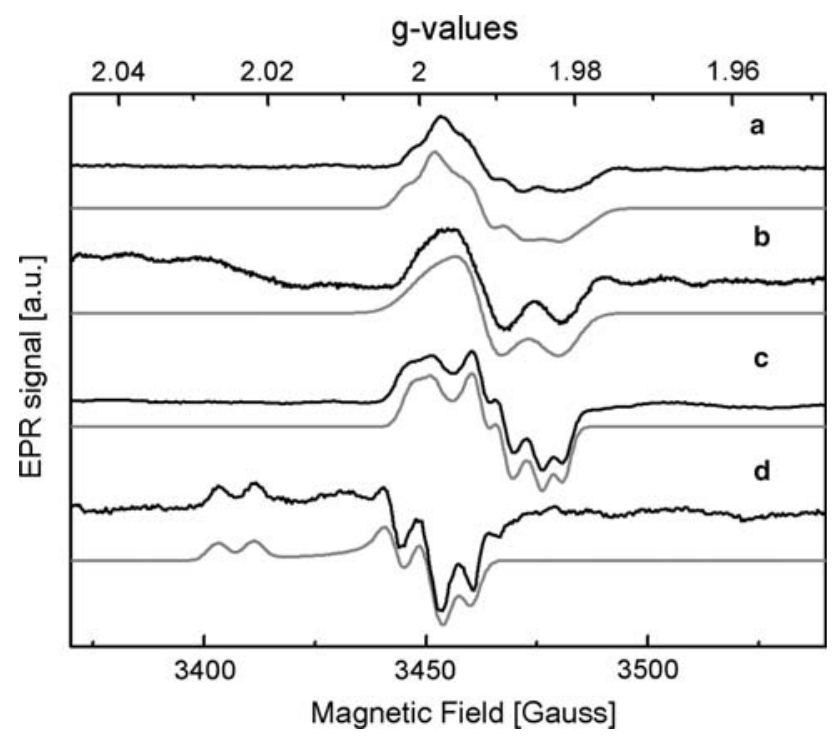

Fig. 5 Electron paramagnetic resonance (EPR) spectra of the Mo(V) species obtained for DdNapA (black lines) together with simulation (gray lines). $a$ Turnover signal, $b$ turnover signal of a $\mathrm{D}_{2} \mathrm{O}$-exchanged sample, $c$ nitrate signal, and $d$ cyanide signal. Simulations were performed assuming collinear $g$ and $A$ tensors and Gaussian line shapes. $A$ values and line widths (in parentheses) are in gauss. The $A$ values for spectrum $a$ correspond to two equivalent protons. The EPR parameters are as follows: spectrum $a, g_{1}=1.999$ (4.5), $g_{2}=1.992$ (5.0), $g_{3}=1.982$ (6.0), $A_{1}=5.8, A_{2}=6.5, A_{3}=5.5$; spectrum $b$, $g_{1}=1.999$ (11.0), $g_{2}=1.992$ (7.0), $g_{3}=1.982$ (8.0); spectrum $c$, $g_{1}=2.000 \quad$ (4.4), $g_{2}=1.990 \quad(3.6), \quad g_{3}=1.981 \quad(3.4), A_{1}=4.6$, $A_{2}=5.0, A_{3}=4.6$; spectrum $d, g_{1}=2.024$ (4.5), $g_{2}=2.001$ (4.0), $g_{3}=1.995(4.0), A_{1}=8.0, A_{2}=7.5, A_{3}=6.0$

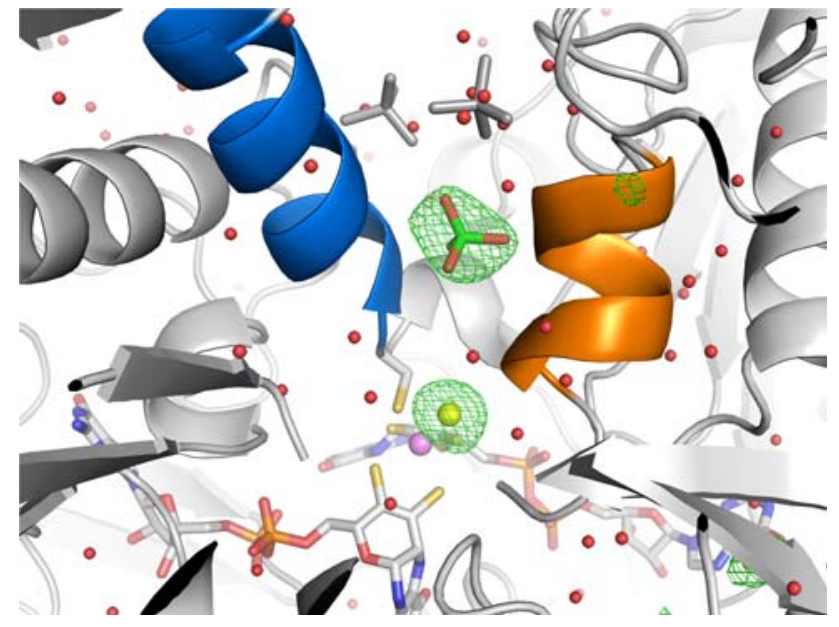

Fig. 6 Closeup of the area of the funnel leading to the active site of the perchlorate-bound DdNapA. The $\mathrm{mFo}-\mathrm{DFc}$ electron density map for PERCHLORATE (old) is represented in green, at $3 \sigma$, and was calculated omitting the sulfur atom (yellow sphere) and the perchlorate. Two of the other three perchlorate ions (in gray) with partial occupancy are also depicted from the PERCHLORATE (fresh) data. The two helices (residues 136-152, in blue, from domain III and residues $348-353$, in orange, from domain II) provide the amino acid residues, which restrict the entry of the perchlorate ion into the active site. The molybdenum atom is depicted as a pink sphere and the water molecules are depicted as red spheres spectrum a). To establish the conditions in which the turnover species is produced, a spectropotentiometric redox titration using zinc-reduced MV was performed. The use of zinc instead of dithionite to reduce MV avoids possible interferences of the EPR-active dithionite-reduced $\mathrm{Mo}(\mathrm{V})$ species, which were shown to be associated with inactive forms of the enzyme [9]. Although the redox potential range of this experiment $(+100,-400 \mathrm{mV})$ covers most of that reached with dithionite, no EPR signals attributable to either the $[4 \mathrm{Fe}-4 \mathrm{~S}]^{+}$cluster $(E=-390 \mathrm{mV})$ or $\mathrm{Mo}(\mathrm{V})$ species were detected. $\mathrm{Mo}(\mathrm{V})$ species called "low potential" are detected with dithionite at approximately $-400 \mathrm{mV}$. This indicates that reduced MV does not interact directly with the redox cofactors of DdNapA and that electron exchange can only occur in the presence of the substrate. To test this hypothesis, nitrate $(100 \mathrm{mM})$ was added to a MV-reduced enzyme sample at $-400 \mathrm{mV}$. This procedure, which raises the solution potential to $-150 \mathrm{mV}$, yields the already reported turnover signal (Fig. 5, spectrum a) (approximately 0.5 spin per molecule, the mean value obtained from several experiments) and concomitantly converts all the MV to its oxidized form, as evidenced by the disappearance of the typical blue color of the reduced solution. Given the experimental impossibility of varying the redox potential in a controlled way, the redox potential of the turnover species could not be determined. However, considering both spin quantification and that the turnover signal disappears after exposing the sample to air, it can be assumed that this signal is associated with $\mathrm{Mo}(\mathrm{V})$ ion species in equilibrium with $\mathrm{Mo}(\mathrm{VI})$ and Mo(IV) ions.

\section{Some clues on the molecular structure of the turnover species}

Previous studies reported for DdNapA under turnover conditions showed that the turnover signal presents hyperfine structure with a nucleus whose nature could not be confirmed. Simulation of this signal obtained from asprepared samples of DdNapA suggested a nuclear species with spin $I=1$. However, it could not be confirmed by an experiment conducted with ${ }^{15} \mathrm{~N}$-labeled nitrate because of a strong signal from the dye overlapping that of the $\mathrm{Mo}(\mathrm{V})$ ion [9]. With use of the optimized conditions of the spectropotentiometric titration, the turnover signal was developed with ${ }^{15} \mathrm{~N}$-labeled nitrate and in $\mathrm{D}_{2} \mathrm{O}$-exchanged DdNapA samples. No differences were found between the spectra obtained with ${ }^{14} \mathrm{NO}_{3}^{-}$(potassium nitrate with natural abundance isotope composition $99.64 \%$ of ${ }^{14} \mathrm{~N}$ ) (Fig. 5, spectrum a) and ${ }^{15} \mathrm{NO}_{3}{ }^{-}\left({ }^{15} \mathrm{~N}\right.$-enriched potassium nitrate, 99\%) (data not shown), excluding the possibility that these signals are associated with a $\mathrm{Mo}(\mathrm{V})$-nitrate adduct. A different result was obtained in the $\mathrm{D}_{2} \mathrm{O}$ 
experiment, which shows that the hyperfine structure of the turnover signal is associated with two equivalent solventexchangeable protons (Fig. 5, spectrum b). All EPR parameters obtained from spectral simulation are given in the caption to Fig. 5.

Reduction of the enzyme with dithionite followed by nitrate addition yields the redox stable nitrate signal which quantifies around 0.4 spin per molecule, and shows hyperfine structure with nonsolvent nuclear species with $I=1 / 2$, which were assigned to the hydrogen atoms of the $\beta$-methylene carbon of $\mathrm{Cys}_{\mathrm{A} 140}$ (Fig. 5, spectrum c).

The EPR signals of the turnover and nitrate species have almost identical $g$ values, suggesting similar ground states for $\mathrm{Mo}(\mathrm{V})$ in both species. The magnitude of the superhyperfine coupling $\left(A_{\text {iso }}=5.9 \mathrm{G}\right)$ associated with the two solvent-exchangeable protons in the turnover species (Fig. 5, spectrum a) is comparable to those of the $\beta$ methylene protons from the Cys $\left(A_{\text {iso }}=4.7 \mathrm{G}\right)$ detected in the nitrate species (Fig. 5, spectrum c), suggesting that these protons are associated with a nucleus not beyond three bonds away from the molybdenum ion.

Considering the structure of the oxidized form of the protein, these interacting nuclei could be bound either to the sulfido group, as a water molecule placed in the second coordination sphere of molybdenum, or as a water molecule directly coordinated to the molybdenum atom. This latter possibility might also imply the loss of the bond between the Cys and the molybdenum, since no hyperfine couplings associated with the $\beta$-methylene protons from the Cys were detected. The present data are not conclusive regarding this issue.

\section{Mechanistic implications of a sulfido ligand and a partial $S-S$ bond}

The new coordination sphere of molybdenum proposed on the basis of our studies led us to revise some aspects of the redox chemistry of molybdenum and the currently accepted reaction mechanism for Nap, originally based on the DdNapA structure [4], and recently investigated by quantum mechanical/molecular mechanical methods [32].

An essential aspect, supported by the structural data of the as-prepared enzyme, is the redox interplay of molybdenum and sulfur, whereby the (partial) formation of a disulfide bond can influence the interconversion of Mo(VI) to Mo(IV). This would involve both a molybdenum and ligand-based redox chemistry instead of the currently accepted redox chemistry based solely on the molybdenum atom in the redox cycle of the enzyme.

The first evidence in favor of such an interplay was presented and discussed by Stiefel et al. [33, 34] in 1980 and was based upon the formation of a partial S-S bond in the cysteamine-derived complexes $\mathrm{MoO}_{2}\left(\mathrm{~S}-\mathrm{N}\left(\mathrm{RR}^{\prime}\right)\right)_{2}$

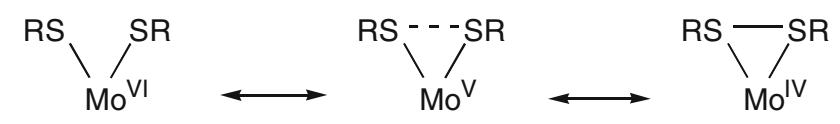

Scheme 1 Molybdenum and ligand-based redox chemistry

[S-N(RR') is ${ }^{-} \mathrm{SC}\left(\mathrm{RR}^{\prime}\right) \mathrm{C}\left(\mathrm{RR}^{\prime}\right) \mathrm{N}\left(\mathrm{RR}^{\prime}\right) ; \mathrm{R}, \mathrm{R}^{\prime}$ are $\left.\mathrm{H}, \mathrm{CH}_{3}\right]$, which strongly departed from the expected octahedral geometry. The $\mathrm{MoO}_{2}\left(\mathrm{~S}-\mathrm{N}\left(\mathrm{RR}^{\prime}\right)\right)_{2}$ complexes present a triatomic motif which supports the metal and sulfur oxidation interplay according to the resonance structures in Scheme 1. Other examples of complexes with Mo-S and S-S distances similar to our results include cis-oxosulfido $\mathrm{Mo}(\mathrm{VI})$ complexes [35]. Two recent reviews (and references therein) provide further examples and address the relevance of redox interplay and molybdenum/sulfur in enzymes in greater detail [36, 37].

Intramolecular electron transfer from sulfur to molybdenum may hypothetically form a full $\mathrm{S}-\mathrm{S}$ bond from an initially expected $\mathrm{Mo}(\mathrm{VI})$ species and, accordingly, an incomplete $\mathrm{S}-\mathrm{S}$ bond reveals a partial intramolecular reduction of the molybdenum and thiolate oxidation.

The occupation of the first coordination sphere of the molybdenum atom in the DdNapA enzyme in its oxidized (as-prepared) form by six sulfur atoms would normally be described by the structure represented as A in Scheme 2 . Two chemical analogues of this thiolate-sulfido complex A [tungsten analogues bis(dithiolene)W(VI)S(SR)] have been recently reported by Groysman and Holm [38] and Jiang and Holm [39]. In these model complexes the RS-S distance is greater than $3.3 \AA$ with no $\mathrm{S}-\mathrm{S}$ interaction. The absence of this interaction in the tungsten complexes can be explained by their lower redox potential and plausibly by a stronger $\mathrm{W}=\mathrm{S}$ bond, compared with their molybdenum analogues. Both differences, known experimentally for a long time, have recently been explained for this type of complex on the basis of the relativistic effects that need to be considered when dealing with third-row transition metals [40].

The X-ray crystal structure of the DdNapA enzyme clearly displays a degree of S-S interaction that reveals some reduction of the Mo(VI) center by an intramolecular redox process involving the thiolate and sulfido ligands, as depicted in Scheme 2. The corresponding formal oxidation state of molybdenum in the as-prepared form is not known and will depend on the degree of S-S bonding. In the hypothetical limit, the formation of a full (shorter) S-S bond by this intramolecular redox process would lead to structure $\mathrm{C}$ with formally a Mo(IV) center.

Another essential aspect of DdNapA now elucidated is that the enzyme only becomes active after reaction with reduced MV in the presence of nitrate. The fact that both substrates must be simultaneously present to exchange 


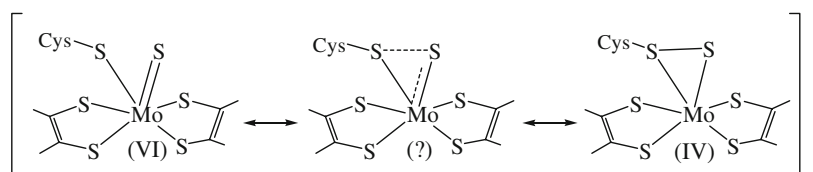

A

B

C

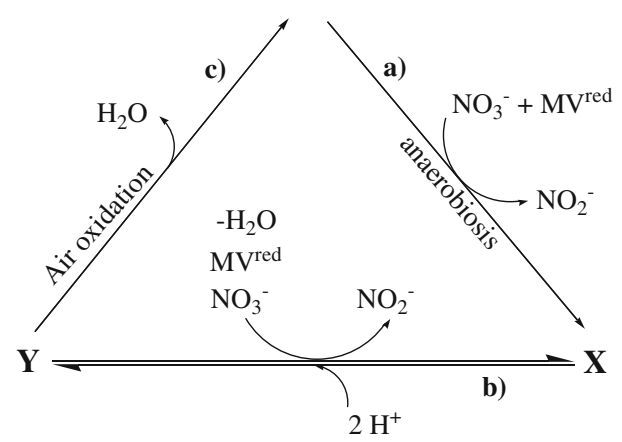

i)

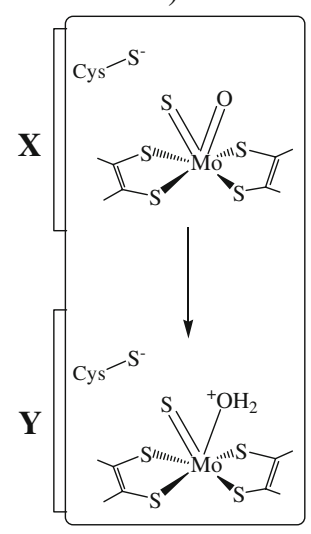

ii)

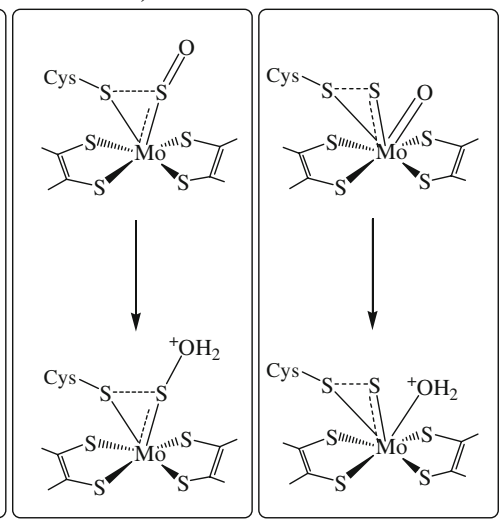

Scheme 2 Alternative reaction mechanisms involving periplasmic nitrate reductases, where $Y$ corresponds to the turnover species, which represents the ready state to initiate the reaction, and $X$ corresponds to the intermediate obtained immediately after nitrite release. Mechanisms $i$ and $i i$ are proposed mechanisms where nitrate binds directly the molybdenum ion with the Cys off and on, respectively; $i i$ corresponds to a proposed mechanism occurring in the second coordination sphere. Step $a$ in the upper scheme represents the activation of the enzyme by methyl viologen $(M V)$ and nitrate under anaerobic conditions, which are then consumed by the enzyme turnover represented by steps $b$. Step $c$ represents the air-oxidation process

electrons with the enzyme indicates that the as-prepared form of DdNapA is in an inactive state, which becomes active to give the EPR-detectable turnover species (see EPR experiment in turnover conditions). This species is redox-active and in the presence of oxygen yields the asprepared form of the enzyme as seen in the experiments in turnover conditions [9].

As there are no structures for the reduced active-site enzyme and the turnover species, only speculative proposals can be made for the reaction mechanism of DdNapA. The process of enzyme activation/inactivation and three different mechanistic alternatives are summarized in Scheme 2. In this scheme, "Y" corresponds to the turnover species, which represents the ready state to initiate the reaction and " $\mathrm{X}$ " corresponds to the intermediate obtained immediately after nitrite release. The proposed structures for both species reflect the different alternatives for nitrate catalysis. The fact that the turnover species does not show hyperfine coupling with the nitrogen nucleus $(I=1)$ of the nitrate ion suggests that the interaction between the active site and nitrate occurs with a more reduced species. However, it cannot be excluded that the nitrate ion interacts with the molybdenum center of the turnover species and the electron spin density of the $\operatorname{Mo}(\mathrm{V})$ ion is not delocalized onto the nitrogen nucleus, resulting in a negligible hyperfine interaction. The nitrate reduction (first or second sphere coordination mechanisms) can occur either through a direct $\mathrm{Mo}-\mathrm{ONO}_{2}{ }^{-}$bond (Scheme 2, alternatives $\mathrm{i}$ and iii) or by bonding of the nitrate ion to a sulfur ligand of molybdenum (Scheme 2, alternative ii). Alternative i (Cys off) would imply the breaking of the Mo-Cys bond with this ligand position being occupied by an oxygen ligand abstracted from nitrate, after nitrite release. This possibility, which is related to that proposed for EcFdh-H [8], is supported by the lack of detection of hyperfine coupling with non-solvent-exchangeable methylene protons from the Cys. Alternatives ii and iii (Cys on) would imply that the Cys is coordinated to molybdenum during the redox cycle of the enzyme. Alternative ii implies the formation of a $\mathrm{Mo} \cdots \mathrm{S} \cdots \mathrm{ONO}_{2}{ }^{-}$adduct through the sulfur atom of the sixth position (second-sphere coordination), whereas alternative iii implies the direct coordination of the nitrate ion in a seventh coordinating mode. Alternative iii was suggested by EXAFS data in the closely related $P$. pantotrophus Nap, which shows heptacoordinated molybdenum sites in several forms of the enzyme [10]. Alternative ii, which has never been suggested for a molybdenum enzyme, would imply a ligand-based redox chemistry instead of that based only on the molybdenum atom with the formation of complexes with a hypervalent sulfur ligand. These types of complexes have been reported for several mononuclear oxodisulfido-molybdenum(VI) complexes [41-44]. One cannot rule out the possibility of alternative ii with the Cys off either, as there are examples of five-coordinated dithiolene complexes with $\mathrm{Mo}=\mathrm{S}$ and without a thiolate ligand [45]. Scheme 2 also shows the activation/inactivation steps under aerobic and anaerobic conditions.

\section{Final remarks}

This work provides strong evidence that the sixth ligand of DdNapA is a sulfur atom instead of the originally proposed oxygen ligand $\left(\mathrm{OH} / \mathrm{OH}_{2}\right)$. In addition, the new 
structural data show that this sulfur ligand forms a partial disulfide bond with the sulfur atom from the Cys coordinated to molybdenum. This coordination motif has never been reported for a member of the DMSO reductase family of mononuclear molybdenum enzymes, the family with the widest structural diversity in terms of active-site coordination [46]. This new structural evidence led us to revise the currently accepted reaction mechanism for Nap.

The reported crystal structures of nitrate-soaked crystals and of inhibited forms of the enzyme reveal that the substrate is guided to the molybdenum active site by electrostatic and hydrogen-bonding interactions between nitrate and specific amino acid residues located on the wall of the channel. In addition, the channel seems to play an important role in selecting the entrance to the molybdenum site by preventing direct contact with the molybdenum atom of larger ions such as perchlorate. The structural analysis of cyanide-inhibited enzyme did not give clear results. It was possible to model a molybdenum ligand, either as a cyanide ion or as a sulfur atom with $75 \%$ occupancy, which can be interpreted as partial cyanolysis.

The fact that Nap from different sources show similar EPR properties $[9,46]$ suggests that different Nap could share the same coordination motif and hence reaction mechanism. While the two other reported crystal structures of a Nap [5, 6] were not solved to high enough resolution (3.2 and $2.5 \AA$, respectively), the crystal structure of $\mathrm{Cu}$ priavidus necator NapAB (unpublished results), revealed the same coordination motif to nearly atomic resolution $(1.5 \AA)$.

In the case of the membrane-bound NR from E. coli, for which there are structures of the whole complex NarGHI [47], and the heterodimeric NarGH [48], there are differences in the molybdenum active site. Both enzymes also show a distorted hexacoordinated molybdenum site. The fifth and sixth positions are occupied by the bidentate coordination from the carboxylate of an aspartic acid residue in NarGHI, whereas in NarGH the side chain carboxylate is monocoordinated and the sixth position is occupied by an oxygenic species. The differences in the molybdenum coordination sphere between Nar and Nap suggest that both enzymes may follow a different reaction mechanism and, in the case of Nar, probably involve a direct nitrate-molybdenum interaction.

The present results demonstrate that distinct aspects attributed to the chemistry of molybdenum inorganic complexes to date can also occur in mononuclear molybdenum-enzymes of the DMSO reductase family, opening new research directions in the study of these proteins. Probably, there is no unique pathway for the reaction catalyzed by NRs. Further work is necessary to confirm these hypotheses.
Acknowledgements P.J.G. (SFRH/BD/10825/2002) and S.N. (SFRH/BD/10784/2004) thank FCT for a fellowship grant. C.D.B. and J.J.G.M. thank SECYT (Argentina) and GRICES (Portugal) for a binational grant. This work was supported by project POCI/QUI/ $57641 / 2004$ financed by the program POCI2010 and cofinanced by FEDER (EC HPRN-CT-1999-00084, PDCT/QUI/57701/2004, POCTI/1999/BME/35078, POCI/QUI/55985/2004, and POCTI/1999/ BME/36152) in Portugal, and SEPCYT:PICT 2003-06-13872, CONICET PIP 5370, and CAI+D-UNL in Argentina. C.D.B. is a member of CONICET-Argentina.

\section{References}

1. Zumft WG (1997) Microbiol Mol Biol Rev 61:533-616

2. Gonzalez PJ, Correia C, Moura I, Brondino CD, Moura JJ (2006) J Inorg Biochem 100:1015-1023

3. Richardson DJ (2000) Microbiology 146(Pt 3):551-571

4. Dias JM, Than ME, Humm A, Huber R, Bourenkov GP, Bartunik HD, Bursakov S, Calvete J, Caldeira J, Carneiro C, Moura JJ, Moura I, Romao MJ (1999) Structure 7:65-79

5. Arnoux P, Sabaty M, Alric J, Frangioni B, Guigliarelli B, Adriano JM, Pignol D (2003) Nat Struct Biol 10:928-934

6. Jepson BJ, Mohan S, Clarke TA, Gates AJ, Cole JA, Butler CS, Butt JN, Hemmings AM, Richardson DJ (2007) J Biol Chem 282:6425-6437

7. Raaijmakers H, Macieira S, Dias JM, Teixeira S, Bursakov S, Huber R, Moura JJ, Moura I, Romão MJ (2002) Structure 10:1261-1272

8. Raaijmakers HC, Romão MJ (2006) J Biol Inorg Chem 11:849854

9. Gonzalez PJ, Rivas MG, Brondino CD, Bursakov SA, Moura I, Moura JJ (2006) J Biol Inorg Chem 11:609-616

10. Butler CS, Charnock JM, Bennett B, Sears HJ, Reilly AJ, Ferguson SJ, Garner CD, Lowe DJ, Thomson AJ, Berks BC, Richardson DJ (1999) Biochemistry 38:9000-9012

11. Brondino CD, Rivas MG, Romão MJ, Moura JJ, Moura I (2006) Acc Chem Res 39:788-796

12. Frangioni B, Arnoux P, Sabaty M, Pignol D, Bertrand P, Guigliarelli B, Leger C (2004) J Am Chem Soc 126:1328-1329

13. Jepson BJ, Anderson LJ, Rubio LM, Taylor CJ, Butler CS, Flores E, Herrero A, Butt JN, Richardson DJ (2004) J Biol Chem 279:32212-32218

14. Liu MC, Peck HD Jr (1981) J Biol Chem 256:13159-13164

15. Dias JM, Bursakov S, Carneiro C, Moura JJ, Moura I, Romão MJ (1999) Acta Crystallogr D Biol Crystallogr 55:877-879

16. Leslie AGW (1992) Joint CCP4 and ESF-EACBM newsletters on protein crystallography 26

17. Kabsch W (1978) Acta Crystallogr A34:827-828

18. Collaborative-Computational-Project-4 (1994) Acta Crystallogr D Biol Crystallogr 50:760-763

19. Murshudov GN, Vagin AA, Dodson EJ (1997) Acta Crystallogr D Biol Crystallogr 53:240-255

20. Jones TA, Zou JY, Cowan SW, Kjeldgaard M (1991) Acta Crystallogr A47:110-119

21. Emsley P, Cowtan K (2004) Acta Crystallogr Sect D Biol Crystallogr 60:2126-2132

22. Schneider TR (2000) Acta Crystallogr D Biol Crystallogr 56:714-721

23. Schneider TR (2002) Acta Crystallogr D Biol Crystallogr 58:195-208

24. Astashkin AV, Klein EL, Enemark JH (2007) J Inorg Biochem 101:1623-1629

25. Bray RC, Gutteridge S, Lamy MT, Wilkinson T (1983) Biochem J 211:227-236 
26. Coelho C, Gonzalez PJ, Trincão J, Carvalho AL, Najmudin S, Hettman T, Dieckman S, Moura JJ, Moura I, Romão MJ (2007) Acta Crystallogr Sect F Struct Biol Crystallogr Commun 63:516519

27. George GN, Colangelo CM, Dong J, Scott RA, Khangulov SV, Gladyshev VN, Stadtman TC (1998) J Am Chem Soc 120:12671273

28. George GN, Costa C, Moura JJG, Moura I (1999) J Am Chem Soc 121:2625-2626

29. Bursakov SA, Carneiro C, Almendra MJ, Duarte RO, Caldeira J, Moura I, Moura JJ (1997) Biochem Biophys Res Commun 239:816-822

30. Gonzalez PJ (2006) Chemistry. Universidade Nova de Lisboa, Lisbon, p 114

31. Hille R (1996) Chem Rev 96:2757-2816

32. Hofmann M (2007) J Biol Inorg Chem 12:989-1001

33. Stiefel EI, Miller KF, Bruce AE, Corbin JL, Berg JM, Hodgson KO (1980) J Am Chem Soc 102(10):3624-3626

34. Berg JM, Spira DJ, Hodgson KO, Bruce AE, Miller KF, Corbin JL, Stiefel EI (1984) Inorg Chem 23:3412-3418

35. Laughlin LJ, Eagle AA, George GN, Tiekink ER, Young CG (2007) Inorg Chem 46:939-948

36. Stiefel EI (2007) In: Bertini I, Gray HB, Stiefel EI, Valentine JS (eds) Biological inorganic chemistry: structure and reactivity. University Science Books, Sausalito, pp 1-30
37. Young CG (2007) J Inorg Biochem 101:1562-1585

38. Groysman S, Holm RH (2007) Inorg Chem 46:4090-4102

39. Jiang J, Holm RH (2004) Inorg Chem 43:1302-1310

40. Tenderholt AL, Szilagyi RK, Holm RH, Hodgson KO, Hedman B, Solomon EI (2007) J Inorg Biochem 101:1594-1600

41. Brown DS, Owens CF, Wilson BG, Welker ME (1990) Organometallics 10:875-879

42. Faller JW, Ma Y (1989) Organometallics 8:609-612

43. Rys AZ, Lebuis AM, Shaver A, Harpp DN (1999) Organometallics 18:1113-1115

44. Halcrow MA, Huffman JC, Christou G (1994) Inorg Chem 33:3639-3644

45. Sugimoto H, Sakurai T, Miyake H, Tanaka K, Tsukube H (2005) Inorg Chem 44:6927-6929

46. Moura JJ, Brondino CD, Trincão J, Romão MJ (2004) J Biol Inorg Chem 9:791-799

47. Bertero MG, Rothery RA, Palak M, Hou C, Lim D, Blasco F, Weiner JH, Strynadka NC (2003) Nat Struct Biol 10:681-687

48. Jormakka M, Richardson D, Byrne B, Iwata S (2004) Structure 12:95-104

49. Delano WL (2002) The PyMOL molecular graphics system. Delano Scientific, San Carlos 